\title{
Computation of Various Domination Numbers of Rolf Nevanlinna (RNP) Collaboration Graph
}

Yegnanarayanan $\mathbf{V}^{1}$, Logeshwary, $\mathbf{B}^{2}$.

${ }^{I}$ SASTRA University - SCHOOL OF HUMANITIES AND SCIENCES, Thirumalai Samudram Thanjavu, Thanjavur, India $;{ }^{2}$ Bharathiar University - Research \& Development Centre, Coimbatore, Tamil Nadu, India.

\begin{abstract}
In this paper, we compute various Domination numbers like Outer Connected Domination (OCD), Doubly Connected Domination (DCD), Fair Domination (FD), Independence Domination (ID), 2-Packing (2-P) for Rolf Nevanlinna Prize Winners's Collaboration Graph (RNPCG).

Keywords: Outer Connected Domination number, Doubly Connected Domination Number, Fair Domination Number, Independence Domination Number, 2-Packing Number, Rolf Nevanlinna collaboration Graph
\end{abstract}

*Author for correspondence: prof.yegna@gmail.com, yegnanarayanan@hotmail.com 


\section{INTRODUCTION}

Graph theory is a fascinating branch of mathematics and computer applications. It has immense potential for applications to engineering, physical, social and biological sciences [1- 4]. The study of domination numbers of graphs assumes a lot of significance as a number of its variations are applied to practical problems. A latest book on domination [5] has lead to the enormous growth of this branch of study. For instance, the notion of domination occurs in facility location problems, where the number of facilities such as hospitals and fire stations is limited and it is required to optimize the distance one requires to cover to reach to the nearest facility. The concept of various domination parameters to ad hoc networks, biological networks, social networks etc., sufficiently describe the growing interest. These applications attempt to choose a subset of vertices that offers useful service such that every vertex in the network is as close as possible to some vertex in the subset. The following examples show when the concept of domination can be applied in modeling real-life problems. Graph theory can be used as a tool to model secondary RNA (Ribonucleic acid) motifs numerically. The graphical invariants employed are variations of the domination number of a graph. These variations correctly distinguish native structures among the trees and segregates those that cannot represent RNA. Dominating sets model social networks and study its dynamics of relations imminent on individuals in different domains.

\section{Erdos Number ad Its Importance}

A Person $\mathrm{x}$ is said to have Erdos number $\mathrm{r}+1$ if $\mathrm{r}$ is the lowest Erdos number of the co-author of $x$. Erdos number actually elaborates the collaborative distance between Erdos and another individual by virtue of co-authoring research papers in mathematics. The notion of defining Erdos number and its computation is meant to pay encomiums to Erdos for his voluminous work in mathematics. The Erdos collaboration graph reveals how mathematics researchers cluster and the pattern of evolution over time of the number of co-authors per paper. It is sad to observe that achieving small Erdos number is becoming increasingly difficult as mathematicians and scientists with low Erdos number disappear from this world. Among Nobel prize laureates in physics, A.Einstein and S.L.Glashow have Erdos number 2, the computational biologist L.Pachter has Erdos number 2, Nobel laureate H.O.Smith in medicine has Erdos number 3. B.Wellman, a well known sociologist has Erdos number 3. It is interesting to note that famous Number theorist Terrance Tao, who was taught by Erdos himself when he was 10 years old at that time has Erdos number 2. It is worth mentioning that several non mathematicians in many fields of science have finite Erdos numbers. Many bio-medical statisticians are linked to Erdos through famous John Turkey who has Erdos number 2. Many geneticists have small Erdos number via the link Eric Lander, a widely known geneticist wit Erdos number 2. All Fields Medal and Rolf Nevanlinna prize winners between 1986and 1994 have Erdos numbers at most 9.

\section{Importance of Centrality and its Limitations}

In Erdos collaboration graph that we consider below the vertex represented by Erdos is the central vertex. The concept of centrality in network analysis identifies the most important vertex/vertices The most influential person in our RNPCG discussed below is a social network. The indices of centrality provide answers to: What are the characteristics of a pertinent vertex? The answer is provided in the form of a realvalued function on the set of vertices of a graph. The values are supposed to provide a ranking which identifies the most important vertices. The RNPCG network is a description of the paths among the participants where transfer of knowledge happens 
Computation of various domination numbers

in joint research work. Such centrality indices have two limitations, one trivial and the other non trivial. The trivial limitation is that a centrality which is optimal for one situation may not be so for a different scenario. A nontrivial limitation is the generally held opinion that vertex centrality indicates the relative importance of vertices. They are meant to yield a ranking which characterizes the pertinent vertices. This happens under the limitation just observed. Even though in the RNPCG Erdos is the central vertex for obvious reasons the challenge lies in the identification of the next most influential vertex and so on. There are two drawbacks in the process. First, a ranking orders vertices only by importance. It is not quantifying the difference in importance among various levels of ranking. Centralization concept due to Freeman gives insight based on the difference in scores of their centralization. It allows one to draw comparison with other networks by considering their maximum centralization scores. Somehow for strange reasons it is never seen in practice. Next, the features that identifies the most important vertices in RNPCG network cannot be generalized to the other remaining vertices. This describes why, for instance, the first few results alone of a Google image search engine appears in order. Even the pagerank mathematical algorithm proves to be a highly unstable measure, exhibiting rank reversals after small adjustments of the jump parameter. Even though the failure of various centrality measures to generalize to the rest of the RNPCG network may at first seem counter-intuitive, it provides us with a chance to delve into the concept of domination numbers and its variations. As complex RNPCG network have heterogeneous topology, the extent to which the various domination number measure handles the network structure regarding the most important vertices turns out to be sub-optimal for the rest of the network.

\section{Preliminaries}

A Graph $G=(V, E)$ is a finite nonempty set $V(G)$ of elements called vertices, along with a possibly empty set $E(G)$ of distinct unordered pairs of elements of $V(G)$ called edges. Two vertices are said to be adjacent to each other or called neighbors if there is an edge between them. For a graph $G=(V, E)$, let $|V(G)|=n$ and $|E(G)|=m$.

\section{Various Neighbourhoods}

The open neighborhood of a vertex $u \in V(G)$, denoted as $N(u)$, consists of all vertices in $\mathrm{V}(\mathrm{G})$ which are adjacent to $u$ and the closed neighborhood of such a vertex $v$, is $N[v]=N(v) \cup\{v\}$. Let $D$ be a subset of $V(G)$ and $v \in D$. Then a private neighborhood of a vertex $v \in V(G)$ with respect to $D$ denoted by $P_{r}[v, D]$ is defined as follows: $\mathrm{P}_{\mathrm{r}}[\mathrm{v}, \mathrm{D}]=\{\mathrm{w} \in \mathrm{V}(\mathrm{G}): \mathrm{N}(\mathrm{w}) \cap \mathrm{D}=\{\mathrm{v}\}\}$. We note that

a) If $w \in V(G)-D$ and $w$ is adjacent only to $v \in D$, then $w \in P_{r}[v, D]$;

b) If $\mathrm{w} \in \mathrm{D}$ and $\mathrm{w} \neq \mathrm{v}$, then $\mathrm{w} \notin \mathrm{P}_{\mathrm{r}}[\mathrm{v}, \mathrm{D}]$;

c) If $\mathrm{w}=\mathrm{v}$ is not adjacent to any vertex of $\mathrm{D}$, then $\mathrm{w} \in \mathrm{P}_{\mathrm{r}}[\mathrm{v}, \mathrm{D}]$.

\section{Domination Number}

A set $D$ of vertices in a graph $G=(V, E)$ is a dominating set of $G$ if every vertex in $\mathrm{V} \backslash \mathrm{D}$ is adjacent to some vertex in $\mathrm{D}$. This definition of a dominating set forms a basis to several other equivalent forms of the definition of a domination set. A set D $\subseteq \mathrm{V}$ is a dominating set if and only if: i. for every vertex $\mathrm{v} \in \mathrm{V}-\mathrm{D}$ there exists a vertex $\mathrm{u} \in \mathrm{D}$ such that $\mathrm{v}$ is adjacent to $\mathrm{u}$; ii. for every vertex $\mathrm{v} \in \mathrm{V}-\mathrm{D}$, the distance between $\mathrm{v}$ and $\mathrm{D}, \mathrm{d}(\mathrm{v}, \mathrm{D}) \leq 1$; iii. the closed neighborhood of $\mathrm{D}$ equals $\mathrm{V}, \mathrm{N}[\mathrm{D}]=\mathrm{V}$; iv. for every vertex $v \in V-D,|N(v) \cap D|>1$, that is, every vertex $v \in V-D$ is adjacent to at least one vertex in $\mathrm{D}$; $\mathrm{v}$. for every vertex $\mathrm{v} \in \mathrm{V},|\mathrm{N}[\mathrm{v}] \cap \mathrm{D}|>1$. The domination number $\gamma(\mathrm{G})$ of a graph $\mathrm{G}$ equals the minimum cardinality of a 
domination set in $\mathrm{G}$. The idea of domination number in graphs occurred from a chess board problem known as the Queen problem. That is, it is required to find the minimum number of queens needed to be placed on an $8 \times 8$ chess board so that each square is either occupied or attacked by a queen.

\section{Outer Connected Domination Number}

For a given graph $G=(V, E)$, a set $D \subseteq V(G)$ is said to be an outer connected dominating set if $D$ is dominating and the graph induced by $V(G \backslash D)$ is connected. The outer connected domination number of $G$, denoted $\gamma_{c}^{\sim}(G)$ is the cardinality of a minimum outer connected dominating set of $G$ [6]. Note that every graph $G$ has an outer connected dominating set. This is because the set of all vertices of $\mathrm{G}$ is an outer connected dominating set in $\mathrm{G}$. It is obvious that if $\mathrm{G}$ is a graph of order $\mathrm{n}$, then $1 \leq$ $\gamma_{\mathrm{c}}^{\sim}(\mathrm{G}) \leq \mathrm{n}$. In addition, $\gamma_{\mathrm{c}}^{\sim}(\mathrm{G})=1$ if and only if $\mathrm{G}=\mathrm{K}_{1} \vee \mathrm{H}$, where $\mathrm{H}$ is a connected graph of order $\mathrm{n}-1$, while $\gamma_{\mathrm{c}}^{\sim}(\mathrm{G})=\mathrm{n}$ if and only if $\mathrm{G}=\mathrm{K}_{\mathrm{n}}^{\mathrm{c}}$. Hence $\gamma_{\mathrm{c}}^{\sim}(\mathrm{G}) \leq \mathrm{n}-1$ if $\mathrm{G}$ has at least one edge. Also $\gamma_{\mathrm{c}}^{\sim}(\mathrm{G}) \neq \mathrm{n}-2$ if and only if $\mathrm{G}$ has at least one edge which is not an end-edge. In general, $\tilde{\gamma_{c}}(\mathrm{G}) \leq \mathrm{n}-\mathrm{k}$ if and only if there exists a proper connected subgraph $\mathrm{H}$ of $\mathrm{G}$ such that $|\mathrm{V}(\mathrm{H})|=\mathrm{k}$ and every vertex of $\mathrm{H}$ has a neighbor which belongs to $\mathrm{V}(\mathrm{G}) \backslash$ $\mathrm{V}(\mathrm{H})$. It is easy to see that if $\mathrm{G}$ is a connected graph on $\mathrm{n} \geq 2$ vertices, then $\gamma_{\mathrm{c}}^{\sim}(\mathrm{G})=$ $\mathrm{n}-1$ if and only if $\mathrm{G}$ is a star. This is because, if $\mathrm{G}$ is a star $\mathrm{K}_{1, \mathrm{n}-1}$ with $\mathrm{V}\left(\mathrm{k}_{1, \mathrm{n}-1}\right)=\{\mathrm{u}$, $\left.\mathrm{u}_{1} \ldots \mathrm{u}_{\mathrm{n}-1}\right\}$ and edge set $\mathrm{E}\left(\mathrm{k}_{1, \mathrm{n}-1}\right)=\left\{\mathrm{u}, \mathrm{u}_{\mathrm{i}}: 1 \leq \mathrm{i} \leq \mathrm{n}-1\right\}$ then any outer connected dominating set $\mathrm{D}$ of this graph cannot contain $\mathrm{u}$. Further it cannot miss any $\mathrm{u}_{\mathrm{i}}$ for $1 \leq$ $\mathrm{i} \leq \mathrm{n}-1$. Therefore it follows that $\tilde{\gamma_{\mathrm{c}}}(\mathrm{G})=\mathrm{n}-1$. Conversely it is equally trivial to see that if $\gamma_{\mathrm{c}}^{\sim}(G)=n-1$ for a graph $G$ then it must be a star. The problem of finding a minimum Outer-connected Dominating set for an input graph $\mathrm{G}$ is stated as follows. Given a graph $G=(V, E)$ and a positive integer $k$, the problem is to decide whether $\mathrm{G}$ has an outer-connected dominating set of cardinality at most $\mathrm{k}$. This problem is known to be NP-complete for bipartite graphs.

\section{Doubly Connected Domination Number}

We say that a set $D \subseteq V(G)$ is a doubly connected dominating set of $G$ if it is dominating and the induced subgraphs $G[D]$ and $G[V(G) \backslash D]$ are connected. The cardinality of a minimum doubly connected dominating set in $\mathrm{G}$ is called a doubly connected domination number and is denoted by $\gamma_{c c}(G)$ [7]. Since for an arbitrary graph $\mathrm{G}$, every connected dominating set is a dominating set and every doubly connected dominating set is a connected dominating set, we have $\gamma(\mathrm{G}) \leq \gamma_{\mathrm{c}}^{\sim}(\mathrm{G}) \leq$ $\gamma_{c c}(G)$. The notion of outer-connected domination can be employed in the following situation. If we have a computer network in which a main group of fileservers possess access to interact directly with every computer outside their group. Moreover, every two computers outside the main group may interact with each other without the intrusion of any of the fileservers to guard the fileservers from overloading. A main group with minimum number of members with these properties is a minimum outer-connected dominating set for the graph representing the network.

\section{Packing Number}

If we are asked to determine as many independent edges in a graph as possible then what strategy we should adopt ? This issue not only occupies the central position of several applications it also provides scope for some interesting graph theory. This is 
referred as matching problem in graph theory. A generalization of this is to determine in a given graph as many disjoint subgraphs as possible that are isomorphic to every element of a given class of graphs. This is called as packing problem. Suppose that $G_{1}$ and $G_{2}$ are two graphs with $n$ vertices. We say that there is a packing of $\mathrm{G}_{1}$ and $\mathrm{G}_{2}$ If there are copies of $G_{1}$ and $G_{2}$ on the same $n$ vertices that are edge-disjoint. Bollobas and Eldridge showed that, if $G_{1}$ and $G_{2}$ together have at most $2 n-3$ edges and no vertex is joined to all other vertices, then there is a packing of $G_{1}$ and $G_{2}$ of course with few exceptions, Define a 2-packing of a graph $\mathrm{G}$ as a set $\mathrm{X} \subset \mathrm{V}(\mathrm{G})$ of vertices such that $\mathrm{N}[\mathrm{x}] \cap \mathrm{N}[\mathrm{y}]=\varnothing$ for each pair of distinct vertices $\mathrm{x}$, $y \in X$. Alternatively, we can define a 2-packing of $G$ as a set $X$ of vertices in $G$ such that for any pair of vertices $\mathrm{x}$ and $\mathrm{y}$ in $\mathrm{X}, \mathrm{d}(\mathrm{x}, \mathrm{y})>2$. The maximum cardinality of a 2-packing set of $G$ is called the 2-packing number of $G$ and is denoted by $\rho_{2}(G)$.

\section{ROLF NEVANLINNA PRIZE WINNER'S COLLABORATION GRAPH (RNPCG)}

\section{Method of Obtaining RNPCG}

We denote the RNPCG by $G^{*}$. It is constructed as follows: $G^{*}$ has twenty three vertices and forty eight edges. Let $\mathrm{V}\left(\mathrm{G}^{*}\right)=\left\{\mathrm{u}_{1}, \mathrm{u}_{2}, \ldots, \mathrm{u}_{23}\right\}$. Here $\mathrm{u}_{1}=$ Paul Erdos, $\mathrm{u}_{2}$ $=$ Maria Margarat Klawe, $\mathrm{u}_{3}=$ Siemion Fajtlowicz, $\mathrm{u}_{4}=$ Robert Robinson, $\mathrm{u}_{5}=$ George Gunthar Lorentz, $\mathrm{u}_{6}=$ Endre Szemeredi, $\mathrm{u}_{7}=$ Laszlo Lovasz, $\mathrm{u}_{8}=$ Nathan Linial, $\mathrm{u}_{9}=$ Alon Noga, $\mathrm{u}_{10}=$ Boris Aronov, $\mathrm{u}_{11}=$ Andrej Ehrenfeucht, $\mathrm{u}_{12}=$ Mark Jerrum, $\mathrm{u}_{13}=$ Alok Aggarwal, $\mathrm{u}_{14}=$ Robert Endre Tarjan, $\mathrm{u}_{15}=$ Leslie Valiant, $\mathrm{u}_{16}=$ A.A.

Razborov,

$\mathrm{u}_{17}=$ Avi Wigderson, $\mathrm{u}_{18}=$ Peter W. Shor, $\mathrm{u}_{19}=$ Madhu Sudan, $\mathrm{u}_{20}=$ Jon Kleinberg, $\mathrm{u}_{21}=$ Mario Szegedy, $\mathrm{u}_{22}=$ Lance J. Fortnow, $\mathrm{u}_{23}=$ Daniel Spielman. Note that the chronological order of prize winners are defined in order by $\mathrm{u}_{\mathrm{j}}, \mathrm{j}=14$ to 20,23 . Let $\mathrm{E}\left(\mathrm{G}^{*}\right)=\left\{\begin{array}{llllll}\mathrm{e}_{1}, & \mathrm{e}_{2}, & \ldots, & \mathrm{e}_{48}\end{array}\right\}$ where $\mathrm{e}_{1}=\left(\mathrm{u}_{1}, \mathrm{u}_{2}\right), \quad \mathrm{e}_{2}=\left(\mathrm{u}_{1}, \mathrm{u}_{3}\right)$, $\mathrm{e}_{3}=\left(\mathrm{u}_{1}, \mathrm{u}_{4}\right), \mathrm{e}_{4}=\left(\mathrm{u}_{1}, \mathrm{u}_{5}\right), \mathrm{e}_{5}=\left(\mathrm{u}_{1}, \mathrm{u}_{6}\right), \mathrm{e}_{6}=\left(\mathrm{u}_{1}, \mathrm{u}_{7}\right), \mathrm{e}_{7}=\left(\mathrm{u}_{1}, \mathrm{u}_{8}\right), \mathrm{e}_{8}=\left(\mathrm{u}_{1}, \mathrm{u}_{9}\right), \mathrm{e}_{9}=\left(\mathrm{u}_{1}\right.$, $\left.\mathrm{u}_{10}\right), \mathrm{e}_{10}=\left(\mathrm{u}_{2}, \mathrm{u}_{8}\right), \mathrm{e}_{11}=\left(\mathrm{u}_{2}, \mathrm{u}_{13}\right), \mathrm{e}_{12}=\left(\mathrm{u}_{2}, \mathrm{u}_{14}\right), \mathrm{e}_{13}=\left(\mathrm{u}_{2}, \mathrm{u}_{17}\right), \mathrm{e}_{14}=\left(\mathrm{u}_{2}, \mathrm{u}_{18}\right), \mathrm{e}_{15}=\left(\mathrm{u}_{3}\right.$, $\left.\mathrm{u}_{11}\right), \quad \mathrm{e}_{16} \quad=\quad\left(\mathrm{u}_{4}, \quad \mathrm{u}_{12}\right), \quad \mathrm{e}_{17} \quad=\quad\left(\mathrm{u}_{5}, \quad \mathrm{u}_{16}\right)$, $\mathrm{e}_{18}=\left(\mathrm{u}_{6}, \mathrm{u}_{9}\right), \mathrm{e}_{19}=\left(\mathrm{u}_{6}, \mathrm{u}_{16}\right), \mathrm{e}_{20}=\left(\mathrm{u}_{6}, \mathrm{u}_{17}\right), \mathrm{e}_{21}=\left(\mathrm{u}_{7}, \mathrm{u}_{8}\right), \mathrm{e}_{22}=\left(\mathrm{u}_{7}, \mathrm{u}_{9}\right), \mathrm{e}_{23}=\left(\mathrm{u}_{7}, \mathrm{u}_{17}\right)$, $\mathrm{e}_{24} \quad=\quad\left(u_{7}, \quad u_{18}\right)$, $e_{25}=\left(u_{8}, u_{9}\right), e_{26}=\left(u_{8}, u_{13}\right), e_{27}=\left(u_{8}, u_{17}\right), e_{28}=\left(u_{8}, u_{18}\right), e_{29}=\left(u_{9}, u_{10}\right), e_{30}=\left(u_{9}, u_{17}\right)$, $e_{31} \quad=\quad\left(u_{9}, \quad u_{19}\right)$, $\mathrm{e}_{32}=\left(\mathrm{u}_{10}, \mathrm{u}_{13}\right), \mathrm{e}_{33}=\left(\mathrm{u}_{11}, \mathrm{u}_{15}\right), \mathrm{e}_{34}=\left(\mathrm{u}_{12}, \mathrm{u}_{15}\right), \mathrm{e}_{35}=\left(\mathrm{u}_{13}, \mathrm{u}_{17}\right), \mathrm{e}_{36}=\left(\mathrm{u}_{13}, \mathrm{u}_{18}\right), \mathrm{e}_{37}=$ $\left(\mathrm{u}_{13}, \mathrm{u}_{19}\right), \mathrm{e}_{38}=\left(\mathrm{u}_{13}, \mathrm{u}_{20}\right), \mathrm{e}_{39}=\left(\mathrm{u}_{16}, \mathrm{u}_{17}\right), \mathrm{e}_{40}=\left(\mathrm{u}_{17}, \mathrm{u}_{19}\right), \mathrm{e}_{41}=\left(\mathrm{u}_{19}, \mathrm{u}_{20}\right), \mathrm{e}_{42}=\left(\mathrm{u}_{1}, \mathrm{u}_{21}\right)$, $\mathrm{e}_{43}=\left(\mathrm{u}_{7}, \mathrm{u}_{21}\right), \mathrm{e}_{44}=\left(\mathrm{u}_{9}, \mathrm{u}_{21}\right), \mathrm{e}_{45}=\left(\mathrm{u}_{17}, \mathrm{u}_{22}\right), \mathrm{e}_{46}=\left(\mathrm{u}_{19}, \mathrm{u}_{21}\right), \mathrm{e}_{47}=\left(\mathrm{u}_{21}, \mathrm{u}_{22}\right), \mathrm{e}_{48}=\left(\mathrm{u}_{22}\right.$, $\mathrm{u}_{23}$ ). None of the eight RNPW'S have Erdos number 1. Out of the 511 direct coauthors of Paul Erdos, with Erdos Number 1, only ten members are connected by a path of length 1 with the RNPW'S. Out of the eight RNPW'S only five members namely $\mathrm{u}_{14}, \mathrm{u}_{16}, \mathrm{u}_{17}, \mathrm{u}_{18}, \mathrm{u}_{19}$ have Erdos number 2, the remaining members namely $\mathrm{u}_{15}, \mathrm{u}_{20}, \mathrm{u}_{22}, \mathrm{u}_{23}$ have Erdos number $3 . \mathrm{G}^{*}$ is shown in Figure 1. 


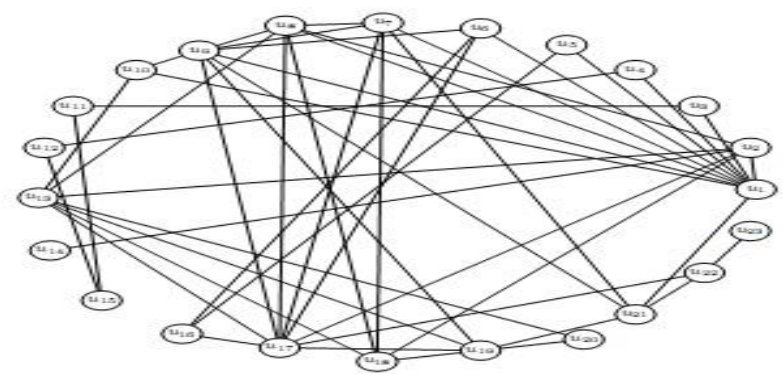

Figure 1. Collaboration Graph

Proceeding like this, one can obtain all the eight RNPW'S collaboration details one by one. We have thoroughly checked all possible combinations. That is, first, we have checked the co author relationship between any of the RNPW'S with any of the 10 applicable co-authors at level 1 with Erdos number 1 . This action leads to $5 \times 10$ $+3 \times 10$ (where $5 \times 10$ stands for the possible collaboration between 5 RNPW's at level 2 with any of the 10 possible collaborators at level 1 and $3 \times 10$ stands for the possible collaboration between 3 RNPW's at level 3 with any of the 10 possible collaborators at level 1) combinations. Then we have considered the possible collaboration of the 4 non RNPW's at level 2 with any of the 10 possible collaborators at level 1 . This action leads to $4 \times 10$ combinations. Then we have to consider possible collaborators between themselves of both 5 RNPW's and 4 non RNPW's at level 2. This action leads to $\left(\begin{array}{l}5 \\ 2\end{array}\right)+\left(\begin{array}{l}4 \\ 2\end{array}\right)+5 \times 4$ combinations. Then we have to consider the possible collaborators between 3 of the RNPW's at level 3 with 5 RNPW's at level 2 and with 4 non RNPW's at level 2 . This action leads to $3 \times 5+$ $3 \times 4$ combinations. Finally we have to consider all possible combinations between themselves of the 3 RNPW's at level 3. This action leads to $\left(\begin{array}{l}3 \\ 2\end{array}\right)$ combinations. A scrupulous implementation of the above said procedure has led to the graph $\mathrm{G}^{*}$ in Figure 1.

\section{Method of drawing the collaboration graph $\mathbf{G}^{*}$}

As $G^{*}$ is fairly a large graph with 23 vertices and 48 edges for manual drawing we employed Pajek program to visualize it. In Windows operating system Pajek is a amenable program for the twin purpose of visualizing and analyzing $G^{*}$. For the latest version of Pajek and for entire procedure of downloading, installing and using one can refer to [7-10]. For more on RNP, for instance, its history and for the details on other related constructions with illustrations one can [10].

\section{Results Concerning G* \\ Outer Connected Domination Number}

Theorem 1[11]. An outer connected dominating set $D$ of $G$ is minimal if and only if for each vertex $v \in D$ one of the following holds good: a) $\operatorname{Pr}[v, D] \neq \varnothing$; b) $v$ is an isolated vertex in the graph induced by $\mathrm{D} ; \mathrm{c}) \mathrm{N}(\mathrm{v}) \cap(\mathrm{V} \backslash \mathrm{D})=\emptyset$.

Proposition 1. $\gamma_{\mathrm{c}}^{\sim}\left(\mathrm{G}^{*}\right)=11$.

Proof. First note that $\mathrm{D}_{1}=\left\{\mathrm{u}_{1}, \mathrm{u}_{3}, \mathrm{u}_{4}, \mathrm{u}_{6}, \mathrm{u}_{11}, \mathrm{u}_{12}, \mathrm{u}_{13}, \mathrm{u}_{14}, \mathrm{u}_{15}, \mathrm{u}_{22}, \mathrm{u}_{23}\right\}$ is an outer connected dominating set. This is because 1$)$ every element of $V\left(G^{*}\right) \backslash D_{1}$ is adjacent with some element of $D_{1}$ as $\left(u_{j}, \quad u_{1}\right)$ for $\mathrm{j}=2,5,7,8,9,10,21 ;\left(\mathrm{u}_{16}, \mathrm{u}_{6}\right) ;\left(\mathrm{u}_{\mathrm{j}}, \mathrm{u}_{13}\right)$ for $\mathrm{j}=17,18,19,20$ are edges of $\mathrm{G}^{*}$ and 2$)$ the subgraph induced by $V\left(G^{*}\right) \backslash D_{1}$ is connected. The graphs induced by $V\left(G^{*}\right) \backslash D_{1}$ and $D_{1}$ are shown in Figure 2. 

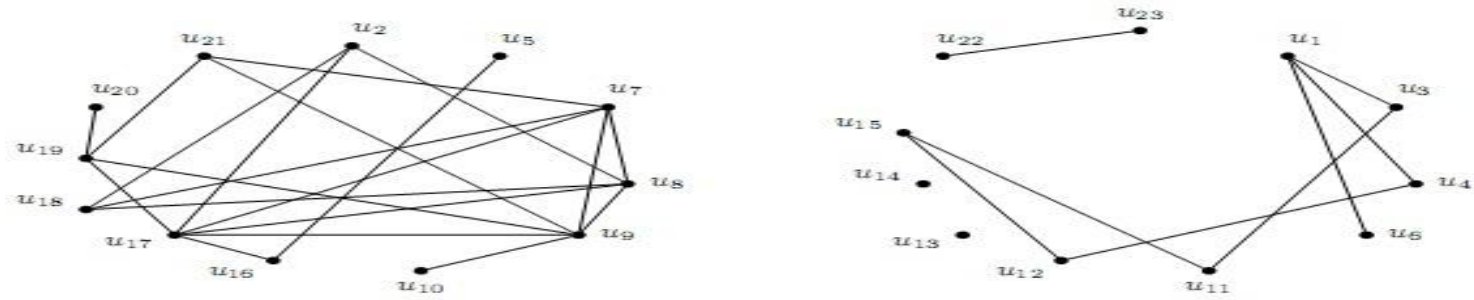

Figure 2. The Graph $V\left(G^{*}\right) \backslash D_{1}$ and The Subgraph Induced by $D_{1}$

Next we claim that $D_{1}$ is a minimal outer connected dominating set using Theorem 1 . Observe that $\mathrm{u}_{13}$ and $\mathrm{u}_{14}$ are isolated vertices in the subgraph induced by $\mathrm{D}_{1}$. Also, $\mathrm{P}_{\mathrm{r}}\left[\mathrm{u}_{1}, \quad \mathrm{D}_{1}\right] \quad \neq \quad \varnothing \quad$ as $\quad \mathrm{u}_{5} \in \mathrm{P}_{\mathrm{r}}\left[\mathrm{u}_{1}, \quad \mathrm{D}_{1}\right]$; $\mathrm{P}_{\mathrm{r}}\left[\mathrm{u}_{22}, \mathrm{D}_{1}\right] \neq \varnothing$ as $\mathrm{u}_{21} \in \mathrm{P}_{\mathrm{r}}\left[\mathrm{u}_{22}, \mathrm{D}_{1}\right] ; \mathrm{P}_{\mathrm{r}}\left[\mathrm{u}_{6}, \mathrm{D}_{1}\right] \neq \varnothing$ as $\mathrm{u}_{16} \in \mathrm{P}_{\mathrm{r}}\left[\mathrm{u}_{6}, \mathrm{D}_{1}\right]$. Further $\mathrm{N}\left(\mathrm{u}_{\mathrm{j}}\right)$ $\cap V\left(G^{*}\right) \backslash D_{1}=\varnothing$ for $j=3,4,11,12,15,23$. Hence $D_{1}$ is a minimal outer connected dominating set. Moreover $\mathrm{D}_{1}$ is not a minimum outer connected dominating set as there exists another such set namely $\mathrm{D}_{2}=\left\{\mathrm{u}_{1}, \mathrm{u}_{3}, \mathrm{u}_{4}, \mathrm{u}_{11}, \mathrm{u}_{12}, \mathrm{u}_{13}, \mathrm{u}_{14}, \mathrm{u}_{15}, \mathrm{u}_{17}, \mathrm{u}_{22}\right.$, $\left.u_{23}\right\}$. This is because 1) every element of $V\left(G^{*}\right) \backslash D_{2}$ is adjacent with some element of $\mathrm{D}_{2}$ as $\left(\mathrm{u}_{\mathrm{j}}, \mathrm{u}_{1}\right)$ for $\mathrm{j}=2,5,6,7,8,9,10,21 ;\left(\mathrm{u}_{16}, \mathrm{u}_{17}\right) ;\left(\mathrm{u}_{\mathrm{j}}, \mathrm{u}_{13}\right)$ for $\mathrm{j}=18,19,20$ are edges

2) $u_{14}$ is an isolated vertex in the subgraph induced by $D_{2}$ and 3) the subgraph induced by $V\left(G^{*}\right) \backslash D_{2}$ is connected. The graphs induced by $V\left(G^{*}\right) \backslash D_{2}$ and $D_{2}$ are shown in Figure 3.
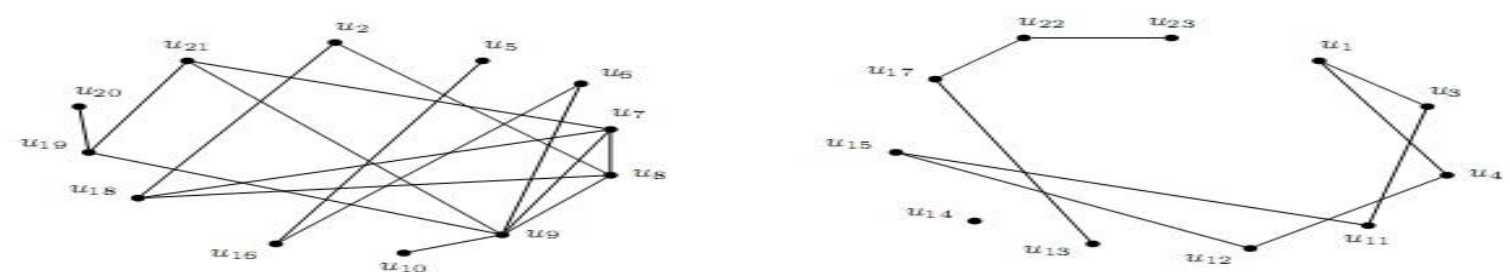

Figure 3. The Graph $V\left(G^{*}\right) \backslash D_{2}$ and The Subgraph Induced by $D_{2}$

Further $\mathrm{P}_{\mathrm{r}}\left[\mathrm{u}_{\mathrm{j}}, \mathrm{D}_{2}\right] \neq \varnothing$ for $\mathrm{j}=1,13,17,22$ as $\mathrm{u}_{\mathrm{i}} \in \mathrm{P}_{\mathrm{r}}\left[\mathrm{u}_{\mathrm{j}}, \mathrm{D}_{2}\right]$ for $\mathrm{i}=5,16,18,21$ respectively in order. Also $\mathrm{N}\left(\mathrm{u}_{\mathrm{j}}\right) \cap \mathrm{V}\left(\mathrm{G}^{*}\right) \backslash \mathrm{D}_{2}=\varnothing$ for $\mathrm{j}=3,4,11,12,15,23$. So $\mathrm{D}_{2}$ satisfies the conditions of Theorem 2.1 and qualifies as a minimal outer connected dominating set. Hence $\gamma_{\mathrm{c}}^{\sim}\left(\mathrm{G}^{*}\right)=11$.

\section{Doubly Connected Domination Number}

Theorem 2 [11]. A doubly connected dominating set $\mathrm{D}$ of $\mathrm{G}$ is minimal if and only if for each vertex $\mathrm{v} \in \mathrm{D}$ one of the following conditions hold good: a) $\operatorname{Pr}[\mathrm{v}, \mathrm{D}] \neq \emptyset$; $) \mathrm{N}(\mathrm{v}) \cap(\mathrm{V} \backslash \mathrm{D})=$ $\emptyset ; c) v$ is a cut vertex of the subgraph induced by $D$.

Proposition 2. $\gamma_{\mathrm{cc}}\left(\mathrm{G}^{*}\right)=12$.

Proof. First note that $\mathrm{D}_{1}=\left\{\mathrm{u}_{1}, \mathrm{u}_{2}, \mathrm{u}_{3}, \mathrm{u}_{4}, \mathrm{u}_{11}, \mathrm{u}_{12}, \mathrm{u}_{13}, \mathrm{u}_{14}, \mathrm{u}_{15}, \mathrm{u}_{17}, \mathrm{u}_{22}, \mathrm{u}_{23}\right\}$ is a doubly connected dominating set. This is because a) every element of $V\left(G^{*}\right) \backslash D_{1}$ is adjacent with some element of $\mathrm{D}_{1}$ as $\left(\mathrm{u}_{\mathrm{j}}, \mathrm{u}_{1}\right)$ for $\mathrm{j}=5,6,7,8,9,10,21 ;\left(\mathrm{u}_{16}, \mathrm{u}_{17}\right) ;\left(\mathrm{u}_{18}, \mathrm{u}_{2}\right) ;\left(\mathrm{u}_{\mathrm{j}}, \mathrm{u}_{13}\right)$ for $\mathrm{j}=19,20$ are edges of $G^{*}$. b) the graphs induced by $D_{1}$ and $V\left(G^{*}\right) \backslash D_{1}$ are connected by Figure 4 . Next by Theorem 2, it is enough to verify that the elements of $D_{1}$, satisfies any one of the three conditions mentioned there. Observe that 
(i) $\mathrm{P}_{\mathrm{r}}\left[\mathrm{u}_{\mathrm{j}}, \mathrm{D}_{1}\right] \neq \varnothing$ for $\mathrm{j}=1,13,17,22$ as $\mathrm{u}_{\mathrm{i}} \in \mathrm{P}_{\mathrm{r}}\left[\mathrm{u}_{\mathrm{j}}, \mathrm{D}_{1}\right]$ for $\mathrm{i}=5,16,20,21$ respectively in

order.

(ii) $\mathrm{N}\left(\mathrm{u}_{\mathrm{j}}\right) \cap\left(\mathrm{V}\left(\mathrm{G}^{*}\right) \backslash \mathrm{D}_{1}\right)=\varnothing$ for $\mathrm{j}=3,4,11,12,14,15,23$ as $\left(\mathrm{N}\left(\mathrm{u}_{3}\right)=\left\{\mathrm{u}_{1}, \mathrm{u}_{11}\right\}\right) \cap$ $\left(\mathrm{V}\left(\mathrm{G}^{*}\right) \backslash \mathrm{D}_{1}\right)=\varnothing ;\left(\mathrm{N}\left(\mathrm{u}_{4}\right)=\left\{\mathrm{u}_{1}, \mathrm{u}_{12}\right\}\right) \cap\left(\mathrm{V}\left(\mathrm{G}^{*}\right) \backslash \mathrm{D}_{1}\right)=\varnothing ;\left(\mathrm{N}\left(\mathrm{u}_{11}\right)=\left\{\mathrm{u}_{3}, \mathrm{u}_{15}\right\}\right) \cap$ $\left(\mathrm{V}\left(\mathrm{G}^{*}\right) \backslash \mathrm{D}_{1}\right)=\varnothing ;\left(\mathrm{N}\left(\mathrm{u}_{12}\right)=\left\{\mathrm{u}_{4}, \mathrm{u}_{15}\right\}\right) \cap\left(\mathrm{V}\left(\mathrm{G}^{*}\right) \backslash \mathrm{D}_{1}\right)=\varnothing ;\left(\mathrm{N}\left(\mathrm{u}_{14}\right)=\left\{\mathrm{u}_{2}\right\}\right) \cap\left(\mathrm{V}\left(\mathrm{G}^{*}\right)\right.$ $\left.\backslash \mathrm{D}_{1}\right)=\varnothing ;\left(\mathrm{N}\left(\mathrm{u}_{15}\right)=\left\{\mathrm{u}_{11}, \mathrm{u}_{12}\right\}\right) \cap\left(\mathrm{V}\left(\mathrm{G}^{*}\right) \backslash \mathrm{D}_{1}\right)=\varnothing ;\left(\mathrm{N}\left(\mathrm{u}_{23}\right)=\left\{\mathrm{u}_{22}\right\}\right) \cap\left(\mathrm{V}\left(\mathrm{G}^{*}\right) \backslash \mathrm{D}_{1}\right)$ $=\varnothing$. (iii) $u_{2}$ is a cut vertex of the subgraph induced by $D_{1}$. See Figure 4 . Hence $D_{1}$ is a minimal doubly connected dominating set. Moreover we also observe that $D_{1}$ is not a minimum such set as $\mathrm{D}_{2}=\left\{\mathrm{u}_{1}, \mathrm{u}_{2}, \mathrm{u}_{3}, \mathrm{u}_{4}, \mathrm{u}_{11}, \mathrm{u}_{12}, \mathrm{u}_{14}, \mathrm{u}_{15}, \mathrm{u}_{17}, \mathrm{u}_{19}, \mathrm{u}_{22}, \mathrm{u}_{23}\right\}$ is another such set. This is because, a) every element of $V\left(G^{*}\right) \backslash D_{2}$ is adjacent with some element of $D_{2}$ as $\left(u_{j}, u_{1}\right)$ for $j=5,6,7,8,9,10,21 ;\left(u_{16}, u_{17}\right) ;\left(u_{j}, u_{13}\right)$ for $j=19$, 20 are edges of $G^{*}$. b) the graphs induced by $D_{2}$ and $V\left(G^{*}\right) \backslash D_{2}$ are connected as shown in Figure 5. Next by Theorem 2, it is enough to verify that the elements of $D_{2}$, satisfies any one of the three conditions mentioned there. Observe that (i) $\mathrm{P}_{\mathrm{r}}\left[\mathrm{u}_{\mathrm{j}}, \mathrm{D}_{2}\right] \neq$ $\varnothing \quad$ for $\mathrm{j}=1, \quad 2, \quad 17, \quad 19 \quad$ as $\quad \mathrm{u}_{\mathrm{i}} \in \mathrm{P}_{\mathrm{r}}\left[\mathrm{u}_{\mathrm{j}}, \quad \mathrm{D}_{2}\right]$ for $\mathrm{i}=5,16,18,20$ respectively in order. (ii) $\mathrm{N}\left(\mathrm{u}_{\mathrm{j}}\right) \cap\left(\mathrm{V}\left(\mathrm{G}^{*}\right) \backslash \mathrm{D}_{2}\right)=\varnothing$ for $\mathrm{j}=3,4,11$, $12,14,15,23$ as $\left(\mathrm{N}\left(\mathrm{u}_{3}\right)=\left\{\mathrm{u}_{1}, \mathrm{u}_{11}\right\}\right) \cap\left(\mathrm{V}\left(\mathrm{G}^{*}\right) \backslash \mathrm{D}_{2}\right)=\varnothing ;\left(\mathrm{N}\left(\mathrm{u}_{4}\right)=\left\{\mathrm{u}_{1}, \mathrm{u}_{12}\right\}\right) \cap$ $\left(\mathrm{V}\left(\mathrm{G}^{*}\right) \backslash \mathrm{D}_{2}\right)=\varnothing ;\left(\mathrm{N}\left(\mathrm{u}^{11}\right)=\left\{\mathrm{u}_{3}, \mathrm{u}_{15}\right\}\right) \cap\left(\mathrm{V}\left(\mathrm{G}^{*}\right) \backslash \mathrm{D}_{2}\right)=\varnothing ;\left(\mathrm{N}\left(\mathrm{u}_{12}\right)=\left\{\mathrm{u}_{4}, \mathrm{u}_{15}\right\}\right) \cap$ $\left(\mathrm{V}\left(\mathrm{G}^{*}\right) \backslash \mathrm{D}_{2}\right)=\varnothing ;\left(\mathrm{N}\left(\mathrm{u}_{14}\right)=\left\{\mathrm{u}_{2}\right\}\right) \cap\left(\mathrm{V}\left(\mathrm{G}^{*}\right) \backslash \mathrm{D}_{2}\right)=\varnothing ;\left(\mathrm{N}\left(\mathrm{u}_{15}\right)=\left\{\mathrm{u}_{11}, \mathrm{u}_{12}\right\}\right) \cap\left(\mathrm{V}\left(\mathrm{G}^{*}\right)\right.$ $\left.\backslash \mathrm{D}_{2}\right)=\varnothing ;\left(\mathrm{N}\left(\mathrm{u}_{23}\right)=\left\{\mathrm{u}_{22}\right\}\right) \cap\left(\mathrm{V}\left(\mathrm{G}^{*}\right) \backslash \mathrm{D}_{2}\right)=\varnothing$. (iii) $\mathrm{u}_{22}$ is a cut vertex of the subgraph induced by $D_{2}$. See Figure 5. Hence $\gamma_{c c}\left(G^{*}\right)=12$.
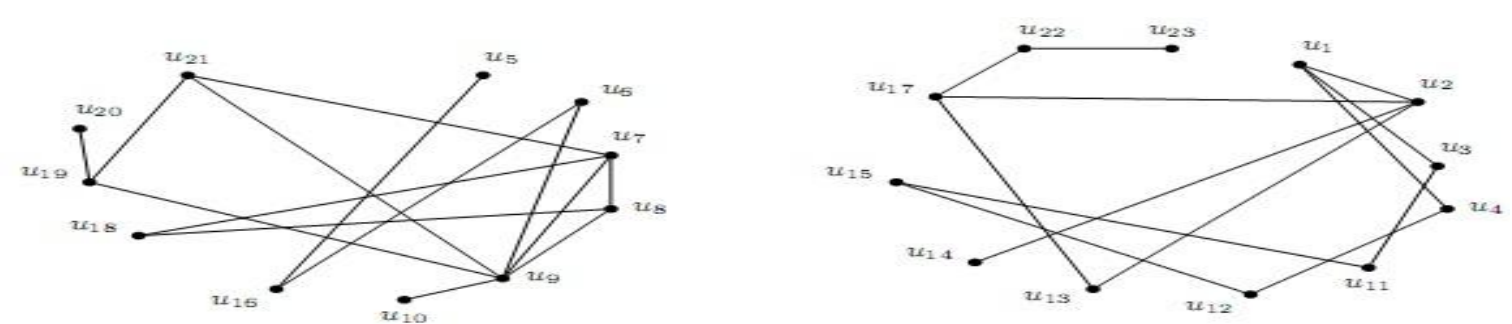

Figure 4. The Graph $V\left(G^{*}\right) \backslash D_{1}$ and The Subgraph Induced by $D_{1}$
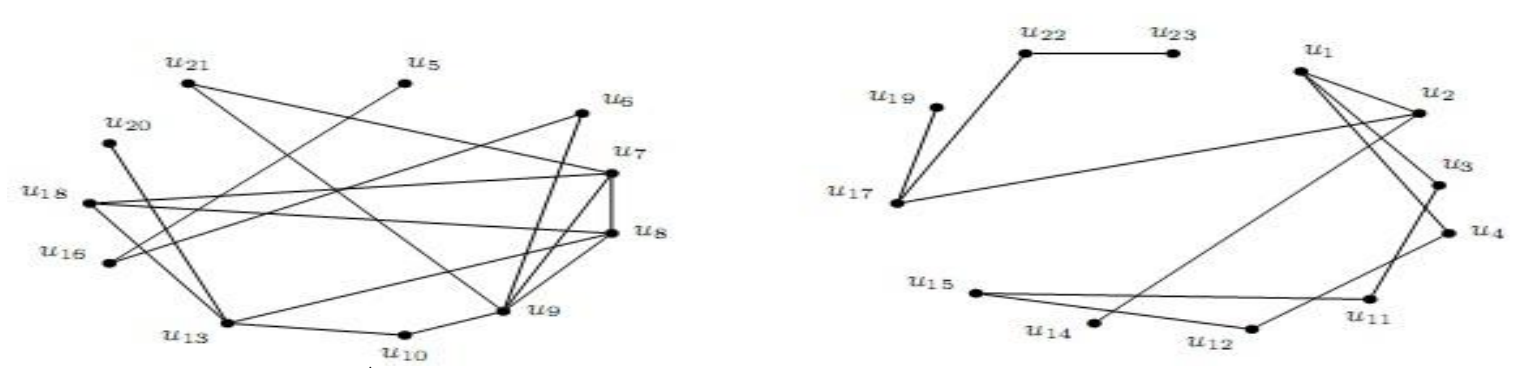

Figure 5. The Graph $V\left(G^{*}\right) \backslash D_{2}$ and The Subgraph Induced by $D_{2}$

\section{Packing Number}

\section{Algorithm 1}

How to Construct a 2-Packing Set?

Step a: Arrange the vertices of a given graph $G$ in the order of non-decreasing degree.

Step b: Identify all pendant vertices in G.

Step c: Form an initial set A with pendant vertices such that their closed neighborhoods are pairwise disjoint. 
Step d: Expand A by adding a vertex u whose degree is greater than the degree of any element of A, provided $\mathrm{N}[\mathrm{u}] \cap \mathrm{N}[\mathrm{v}]=\varnothing$ for all $\mathrm{v} \in \mathrm{V}(\mathrm{G})$ and goto Step e else goto Step f.

Step e: Stop and declare that A is the required set.

Step f: Repeat Step d.

Theorem 3 [11].For any graph $G, \rho_{2}(G) \leq \gamma(G)$.

Proposition 3. $\rho_{2}\left(G^{*}\right)=6$.

Proof. By Theorem 3, we have $\rho_{2}\left(\mathrm{G}^{*}\right) \leq \gamma\left(\mathrm{G}^{*}\right)$. But $\gamma\left(\mathrm{G}^{*}\right)=6$ by Theorem 7.1 of [10]. Therefore a 2-packing set of $G^{*}$ can have at most six elements. Now we construct a 2-packing set $A$ of $G^{*}$ with 6 elements by using the Algorithm 1. The initial set $A$ consists of two one degree vertices namely, $u_{14}, u_{23}$. So $A=\left\{u_{14}, u_{23}\right\}$. There are seven two degree vertices $\left(\mathrm{u}_{3}, \mathrm{u}_{4}, \mathrm{u}_{5}, \mathrm{u}_{11} \mathrm{u}_{12}, \mathrm{u}_{15}, \mathrm{u}_{20}\right)$ out of which $\mathrm{u}_{3}, \mathrm{u}_{4}$, $\left.\mathrm{u}_{11}, \mathrm{u}_{12}\right\}$ and $\mathrm{u}_{20}$ are eligible to be included in $\mathrm{A}$ under the virtue of the fact that $\mathrm{N}\left(\mathrm{u}_{\mathrm{j}}\right)$ $\cap \mathrm{N}\left(\mathrm{u}_{\mathrm{i}}\right)=\varnothing$ for $\mathrm{j}=14,23$ and $\mathrm{i}=3,4,11,12,20$. But as $\left(\mathrm{u}_{3}, \mathrm{u}_{11}\right),\left(\mathrm{u}_{4}, \mathrm{u}_{12}\right) \in \mathrm{E}\left(\mathrm{G}^{*}\right)$ both $\mathrm{u}_{3}$ and $\mathrm{u}_{4}$ cannot be included in A simultaneously. Without loss of generality assume that $\mathrm{u}_{3} \in A$. Then as $\mathrm{N}\left(\mathrm{u}_{\mathrm{j}}\right) \cap \mathrm{N}\left(\mathrm{u}_{\mathrm{i}}\right)=\varnothing$ for $\mathrm{j}=14,23$ and $\mathrm{i}=3,12,20$ the expanded set $A$ takes the form $A^{(1)}=\left\{u_{14}, u_{23}, u_{3}, u_{12}, u_{20}\right\}$. Next we look at the eligible three degree vertices among all the three degree vertices $\left(u_{10}, u_{16}, u_{22}\right)$. As $\mathrm{N}\left(\mathrm{u}_{\mathrm{j}}\right) \cap \mathrm{N}\left(\mathrm{u}_{\mathrm{i}}\right) \quad=\quad \varnothing \quad$ for $j=3,14,23,12,20$ and $i=16$, we expand the set $A$ further and $A^{(2)}=\left\{u_{14}, u_{23}, u_{3}\right.$, $\left.\mathrm{u}_{12}, \mathrm{u}_{20}, \mathrm{u}_{16}\right\}$. Now as the cardinality of $A$ has reached the maximum permissible size of 6, we stop and declare $A$ as the maximal 2-packing set with its elements as $A^{\text {final }}=$ $\mathrm{A}^{(2)}$. Moreover we find another 2-packing set $A_{1}^{\text {final }}=\left\{u_{14}, u_{23}, u_{4}, u_{11}, u_{20}, u_{16}\right\}$ by looking at the other option of choosing $u_{4}$ as the third element of $A_{1}^{\text {final }}$. Hence $\rho_{2}\left(G^{*}\right)=6$.

\section{Fair Domination Number}

First we define the concept of External Domination as follows. We say that the set of vertices $X$ from $G$ externally dominates a set $U \subset V(G)$ if $U \cap X=\varnothing$ and for every $\mathrm{u} \in \mathrm{U}$ there exists $\mathrm{x} \in \mathrm{X}$ such that $\mathrm{ux} \in \mathrm{E}(\mathrm{G})$. Let $\mathrm{D}_{1}, \mathrm{D}_{2}, \ldots, \mathrm{D}_{\mathrm{k}}$ be pairwise disjoint sets of vertices from a graph $G=(V, E)$ with $D^{*}=D_{1} \cup D_{2} \cup \ldots \cup D_{k}$ and let $Z=V \backslash D^{*}$. We say that the sets $\bigcup_{\mathrm{i}=1}^{\mathrm{k}} \mathrm{D}_{\mathrm{i}}$ form a fair reception of size $\mathrm{k}$ if for any integer $l, 1 \leq l \leq$ $\mathrm{k}$, and any choice of $l$ sets $\mathrm{D}_{\mathrm{i}_{\mathrm{r}}} 1 \leq \mathrm{r} \leq l$ the following holds: if $\mathrm{D}$ externally dominates $\bigcup_{\mathrm{r}=1}^{l} \mathrm{D}_{\mathrm{i}_{4}}$ then $|\mathrm{D} \cap \mathrm{Z}|+\sum_{\mathrm{j}, \mathrm{D}, \mathrm{D}, \mathrm{D} \neq \varphi}\left(\left|\mathrm{D}_{\mathrm{j}} \cap \mathrm{D}\right|-1\right) \geq l$. That is, on the left hand side we count all the vertices of $\mathrm{D}$ that are not in $\mathrm{D}^{*}$, and for vertices of $\mathrm{D}$ that are in some $D_{j}$, we count all but one from $D \cap D_{j}$. In any graph, any subset of the vertex set forms a fair reception of size 1 . Given a graph $\mathrm{G}$, the largest $\mathrm{k}$ such that there exists a fair reception of size $k$ in $G$ is denoted by $\gamma_{F}(G)$, and called the Fair Domination number of $\mathrm{G}$. It is known that for any graph $\mathrm{G}, \rho_{2}(\mathrm{G}) \leq \gamma_{\mathrm{F}}(\mathrm{G}) \leq \gamma(\mathrm{G})$. In view of this, we deduce that $\gamma_{\mathrm{F}}\left(\mathrm{G}^{*}\right)=6$ as $\rho_{2}\left(\mathrm{G}^{*}\right)=\gamma\left(\mathrm{G}^{*}\right)=6$ by Theorem 7.1 of [12] and Proposition 4. The following illustration demonstrates the existence of a fair reception of size 6 . 
Let $D_{1}=\left\{u_{11}\right\} ; D_{2}=\left\{u_{1}, u_{14}\right\} ; D_{3}=\left\{u_{2}, u_{12}, u_{18}\right\} ; D_{4}=\left\{u_{8}, u_{16}, u_{20}, u_{21}\right\} ; D_{5}=\left\{u_{3}, u_{6}\right.$, $\left.\mathrm{u}_{7}, \quad \mathrm{u}_{10}, \quad \mathrm{u}_{19}\right\} \quad$ and $D_{6}=\left\{u_{4}, u_{5}, u_{9}, u_{13}, u_{17}, u_{23}\right\}$ be a collection of pairwise disjoint sets of vertices of $G^{*}$ with $\mathrm{D}^{*}=\bigcup_{\mathrm{j}=1}^{6} \mathrm{D}_{\mathrm{j}}$ and $\mathrm{Z}=\mathrm{VD}^{*}$. Let $l$ be any integer such that $1 \leq l \leq 6$. We now construct for each value of $l$ an appropriate set $\mathrm{D}$ that externally dominates $\bigcup_{\mathrm{r}=1}^{l} \mathrm{D}_{\mathrm{i}}$ and satisfy the inequality $|\mathrm{D} \cap \mathrm{Z}|+\sum_{\mathrm{j}, \mathrm{D}_{\mathrm{j}} \cap \mathrm{D} \neq \mathrm{p}}\left(\mathrm{D}_{\mathrm{j}} \cap \mathrm{D} \mid-1\right) \geq l$.

Set $l=1$. Choose $\mathrm{D}=\left\{\mathrm{u}_{1}, \mathrm{u}_{3}, \mathrm{u}_{8}, \mathrm{u}_{12}, \mathrm{u}_{15}, \mathrm{u}_{23}\right\}$. Note that $\mathrm{D}$ externally dominates $\bigcup_{\mathrm{k}=1}^{l=1} \mathrm{D}_{\mathrm{i}_{\mathrm{k}}}=\mathrm{D}_{l_{1}}=\left\{\mathrm{u}_{11}\right\}$ as $\left(\mathrm{u}_{11}, \mathrm{u}_{15}\right) \in \mathrm{E}\left(\mathrm{G}^{*}\right)$. Also observe that $|\mathrm{D} \cap \mathrm{Z}|+\left(\left|\mathrm{D}_{2} \cap \mathrm{D}\right|-1\right)$ $+\left(\left|\mathrm{D}_{3} \cap \mathrm{D}\right|-1\right)+\left(\left|\mathrm{D}_{4} \cap \mathrm{D}\right|-1\right)+\left(\left|\mathrm{D}_{5} \cap \mathrm{D}\right|-1\right)+\left(\left|\mathrm{D}_{6} \cap \mathrm{D}\right|-1\right)=1+(1-1)+$ $(1-1)+(1-1)+(1-1)+(1-1) \geq 1$.

Set $l=2$. Choose $D=\left\{u_{2}, u_{11}, u_{15}, u_{17}, u_{18}, u_{19}, u_{21}\right\}$. Note that $D$ externally dominates $\bigcup_{\mathrm{k}=1}^{l=2} \mathrm{D}_{\mathrm{i}_{\mathrm{k}}}$ where $\mathrm{D}_{2_{1}}=\left\{\mathrm{u}_{1}\right\}, \mathrm{D}_{2_{2}}=\left\{\mathrm{u}_{14}\right\}$ as $\left(\mathrm{u}_{1}, \mathrm{u}_{21}\right)$ and $\left(\mathrm{u}_{14}, \mathrm{u}_{2}\right) \in \mathrm{E}\left(\mathrm{G}^{*}\right)$. Also observe that $|\mathrm{D} \cap \mathrm{Z}|+\left(\left|\mathrm{D}_{1} \cap \mathrm{D}\right|-1\right)+\left(\left|\mathrm{D}_{3} \cap \mathrm{D}\right|-1\right)+\left(\left|\mathrm{D}_{4} \cap \mathrm{D}\right|-1\right)+\left(\mid \mathrm{D}_{5} \cap\right.$ $\mathrm{D} \mid-1)+\left(\left|\mathrm{D}_{6} \cap \mathrm{D}\right|-1\right)=1+(1-1)+(2-1)+(1-1)+(1-1)+(1-1) \geq 2$.

Set $l=3$. Choose $\mathrm{D}=\left\{\mathrm{u}_{1}, \mathrm{u}_{4}, \mathrm{u}_{6}, \mathrm{u}_{10}, \mathrm{u}_{11}, \mathrm{u}_{13}, \mathrm{u}_{15}, \mathrm{u}_{21}, \mathrm{u}_{23}\right\}$. Note that $\mathrm{D}$ externally dominates $\bigcup_{\mathrm{k}=1}^{l=3} \mathrm{D}_{\mathrm{i}_{\mathrm{k}}}$ where $\mathrm{D}_{3_{1}}=\left\{\mathrm{u}_{2}\right\}, \mathrm{D}_{3_{2}}=\left\{\mathrm{u}_{12}\right\}, \mathrm{D}_{3_{3}}=\left\{\mathrm{u}_{18}\right\}$ as $\left(\mathrm{u}_{2}, \mathrm{u}_{1}\right),\left(\mathrm{u}_{12}, \mathrm{u}_{15}\right)$ and $\left(\mathrm{u}_{18}, \mathrm{u}_{13}\right) \in \mathrm{E}\left(\mathrm{G}^{*}\right)$. Also observe that $|\mathrm{D} \cap \mathrm{Z}|+\left(\left|\mathrm{D}_{1} \cap \mathrm{D}\right|-1\right)+\left(\left|\mathrm{D}_{2} \cap \mathrm{D}\right|-1\right)+$ $\left(\left|\mathrm{D}_{4} \cap \mathrm{D}\right|-1\right)+\left(\left|\mathrm{D}_{5} \cap \mathrm{D}\right|-1\right)+\left(\left|\mathrm{D}_{6} \cap \mathrm{D}\right|-1\right)=1+(1-1)+(1-1)+(1-1)+(2-1)$ $+(2-1) \geq 3$.

Set $l=4$. Choose $\mathrm{D}=\left\{\mathrm{u}_{6}, \mathrm{u}_{11}, \mathrm{u}_{12}, \mathrm{u}_{13}, \mathrm{u}_{14}, \mathrm{u}_{17}, \mathrm{u}_{18}, \mathrm{u}_{19}, \mathrm{u}_{22}\right\}$. Note that $\mathrm{D}$ externally dominates $\bigcup_{\mathrm{k}=1}^{l=4} \mathrm{D}_{\mathrm{i}_{\mathrm{k}}}$, where $\mathrm{D}_{4_{1}}=\left\{\mathrm{u}_{8}\right\}, \mathrm{D}_{4_{2}}=\left\{\mathrm{u}_{16}\right\}, \mathrm{D}_{4_{3}}=\left\{\mathrm{u}_{20}\right\}, \mathrm{D}_{4_{4}}=\left\{\mathrm{u}_{21}\right\}$ as $\left(\mathrm{u}_{8}\right.$, $\left.\mathrm{u}_{17}\right),\left(\mathrm{u}_{16}, \mathrm{u}_{17}\right),\left(\mathrm{u}_{20}, \mathrm{u}_{19}\right)$ and $\left(\mathrm{u}_{21}, \mathrm{u}_{19}\right) \in \mathrm{E}\left(\mathrm{G}^{*}\right)$. Also observe that $|\mathrm{D} \cap \mathrm{Z}|+\left(\left|\mathrm{D}_{1} \cap \mathrm{D}\right|\right.$ $-1)+\left(\left|\mathrm{D}_{2} \cap \mathrm{D}\right|-1\right)+\left(\left|\mathrm{D}_{3} \cap \mathrm{D}\right|-1\right)+\left(\left|\mathrm{D}_{5} \cap \mathrm{D}\right|-1\right)+\left(\left|\mathrm{D}_{6} \cap \mathrm{D}\right|-1\right)=1+(1-1)+$ $(1-1)+(2-1)+(2-1)+(2-1) \geq 4$.

Set $l=5$. Choose $\mathrm{D}=\left\{\mathrm{u}_{1}, \mathrm{u}_{8}, \mathrm{u}_{9}, \mathrm{u}_{11}, \mathrm{u}_{12}, \mathrm{u}_{15}, \mathrm{u}_{17}, \mathrm{u}_{21}, \mathrm{u}_{22}, \mathrm{u}_{23}\right\}$. Note that $\mathrm{D}$ externally dominates $\bigcup_{k=1}^{l=5} D_{i_{k}}$, where $D_{5_{1}}=\left\{u_{3}\right\}, D_{5_{2}}=\left\{u_{6}\right\}, D_{5_{3}}=\left\{u_{7}\right\}, D_{5_{4}}=\left\{u_{10}\right\}$, $\mathrm{D}_{5_{5}}=\left\{\mathrm{u}_{19}\right\}$ as $\left(\mathrm{u}_{3}, \mathrm{u}_{1}\right),\left(\mathrm{u}_{6}, \mathrm{u}_{1}\right),\left(\mathrm{u}_{7}, \mathrm{u}_{1}\right),\left(\mathrm{u}_{10}, \mathrm{u}_{1}\right)$ and $\left(\mathrm{u}_{19}, \mathrm{u}_{21}\right) \in \mathrm{E}\left(\mathrm{G}^{*}\right)$. Also observe that $|\mathrm{D} \cap \mathrm{Z}|+\left(\left|\mathrm{D}_{1} \cap \mathrm{D}\right|-1\right)+\left(\left|\mathrm{D}_{2} \cap \mathrm{D}\right|-1\right)+\left(\left|\mathrm{D}_{3} \cap \mathrm{D}\right|-1\right)+\left(\left|\mathrm{D}_{4} \cap \mathrm{D}\right|-1\right)+$ $\left(\left|\mathrm{D}_{6} \cap \mathrm{D}\right|-1\right)=2+(1-1)+(1-1)+(1-1)+(2-1)+(3-1) \geq 5$.

Set $l=6$. Choose $D=\left\{\mathrm{u}_{1}, \mathrm{u}_{2}, \mathrm{u}_{3}, \mathrm{u}_{8}, \mathrm{u}_{10}, \mathrm{u}_{11}, \mathrm{u}_{12}, \mathrm{u}_{15}, \mathrm{u}_{16}, \mathrm{u}_{19}, \mathrm{u}_{22}\right\}$. Note that $\mathrm{D}$ externally dominates $\bigcup_{\mathrm{k}=1}^{l=6} \mathrm{D}_{\mathrm{i}_{\mathrm{k}}}$, where $\mathrm{D}_{6_{1}}=\left\{\mathrm{u}_{4}\right\}, \mathrm{D}_{6_{2}}=\left\{\mathrm{u}_{5}\right\}, \mathrm{D}_{6_{3}}=\left\{\mathrm{u}_{9}\right\}, \mathrm{D}_{6_{4}}=\left\{\mathrm{u}_{13}\right\}$

$$
\mathrm{D}_{6_{5}}=\left\{\mathrm{u}_{17}\right\}, \quad \mathrm{D}_{6_{6}}=\left\{\mathrm{u}_{23}\right\} \quad \text { as } \quad\left(\mathrm{u}_{4}, \quad \mathrm{u}_{1}\right) \text {, }
$$

$\left(\mathrm{u}_{5}, \mathrm{u}_{1}\right),\left(\mathrm{u}_{9}, \mathrm{u}_{1}\right),\left(\mathrm{u}_{13}, \mathrm{u}_{2}\right),\left(\mathrm{u}_{17}, \mathrm{u}_{16}\right)$ and $\left(\mathrm{u}_{23}, \mathrm{u}_{22}\right) \in \mathrm{E}\left(\mathrm{G}^{*}\right)$. Also observe that $|\mathrm{D} \cap \mathrm{Z}|$ $+\left(\left|\mathrm{D}_{1} \cap \mathrm{D}\right|-1\right)+\left(\left|\mathrm{D}_{2} \cap \mathrm{D}\right|-1\right)+\left(\left|\mathrm{D}_{3} \cap \mathrm{D}\right|-1\right)+\left(\left|\mathrm{D}_{4} \cap \mathrm{D}\right|-1\right)+\left(\left|\mathrm{D}_{5} \cap \mathrm{D}\right|-1\right)=$ $2+(1-1)+(1-1)+(2-1)+(2-1)+(3-1) \geq 6$. Thus, we have the following proposition: 
Proposition 4. $\gamma_{\mathrm{F}}\left(\mathrm{G}^{*}\right)=6$.

\section{Vertex Independence Number}

Proposition 5. $\beta_{0}\left(G^{*}\right)=10$.

Proof. We know that for any graph $\mathrm{G}, \beta_{0}(\mathrm{G})=\max _{\mathrm{u} \in \mathrm{V}(\mathrm{G})}\left\{\beta_{0}(\mathrm{G}-\mathrm{u}), 1+\beta_{0}(\mathrm{G}-\mathrm{N}[\mathrm{u}])\right\}$. It is enough to look at vertices of high degree in $G^{*}$. The high degree vertices are $u_{1}$ with $\operatorname{deg}\left(\mathrm{u}_{1}\right)=10 ; \mathrm{u}_{17}$ with $\operatorname{deg}\left(\mathrm{u}_{17}\right)=9 ; \mathrm{u}_{9}$ with $\operatorname{deg}\left(\mathrm{u}_{9}\right)=8 ; \mathrm{u}_{8}, \mathrm{u}_{13}$ with $\operatorname{deg}\left(\mathrm{u}_{8}\right)=$ $\operatorname{deg}\left(\mathrm{u}_{13}\right)=7 ; \mathrm{u}_{2}, \mathrm{u}_{7}$ with $\operatorname{deg}\left(\mathrm{u}_{2}\right)=\operatorname{deg}\left(\mathrm{u}_{7}\right)=6 ; \mathrm{u}_{19}, \mathrm{u}_{21}$ with $\operatorname{deg}\left(\mathrm{u}_{19}\right)=\operatorname{deg}\left(\mathrm{u}_{21}\right)=5$. First let us choose $u_{1}$. Consider $G \backslash u_{1}$. The structure of $G^{*}$ reveals that a maximal independent set of $G^{*} \backslash u_{1}$ is $\left\{u_{2}, u_{3}, u_{4}, u_{5}, u_{6}, u_{7}, u_{10}, u_{15}, u_{19}, u_{22}\right\}$ with $\beta_{0}\left(G^{*} \backslash u_{1}\right)=$ 10. Further consider $G^{*} \backslash N\left[u_{1}\right]$. Its maximal independent set is $\left\{u_{11}, u_{12}, u_{13}, u_{14}, u_{16}\right.$, $\left.u_{22}\right\}$ with $\beta_{0}\left(G^{*} \backslash N\left[u_{1}\right]\right)=6$. Therefore $\beta_{0}\left(G^{*}\right)=\max \{10,6\}=10$. Moreover we do the similar analysis with $\mathrm{u}_{17}, \mathrm{u}_{9}, \mathrm{u}_{8}, \mathrm{u}_{13}, \mathrm{u}_{2}, \mathrm{u}_{7}, \mathrm{u}_{19}, \mathrm{u}_{21}$ in order which reveals that their respective $\beta_{0}^{\prime}$ s are 7, 7, 8, 8, 9, 9, 7 and 9 in order. Further the $\beta_{0}$ values for low degree vertices namely $\mathrm{u}_{6}, \mathrm{u}_{18}$ with $\operatorname{deg}\left(\mathrm{u}_{6}\right)=\operatorname{deg}\left(\mathrm{u}_{18}\right)=4 ; \mathrm{u}_{10}, \mathrm{u}_{16}, \mathrm{u}_{22}$ with $\operatorname{deg}\left(\mathrm{u}_{10}\right)$ $=\operatorname{deg}\left(\mathrm{u}_{16}\right)=\operatorname{deg}\left(\mathrm{u}_{22}\right)=3 ; \mathrm{u}_{3}, \mathrm{u}_{4}, \mathrm{u}_{5}, \mathrm{u}_{11}, \mathrm{u}_{12}, \mathrm{u}_{15}, \mathrm{u}_{20}$ with $\operatorname{deg}\left(\mathrm{u}_{3}\right)=\operatorname{deg}\left(\mathrm{u}_{4}\right)=\operatorname{deg}\left(\mathrm{u}_{5}\right)$ $=\operatorname{deg}\left(\mathrm{u}_{11}\right)=\operatorname{deg}\left(\mathrm{u}_{12}\right)=\operatorname{deg}\left(\mathrm{u}_{15}\right)=\operatorname{deg}\left(\mathrm{u}_{20}\right)=2 ; \mathrm{u}_{14}, \mathrm{u}_{23}$ of degree 1 are respectively $9,7,9,6,7,9,9,9,6,6,7,7$ in order. Hence we have thoroughly established that $\beta_{0}\left(G^{*}\right)=10$.

\section{Independence Dominating Number}

Given a graph $\mathrm{G}$ and an independent set $\mathrm{I}$ of vertices in $\mathrm{G}$, the least size of a set of vertices in $\mathrm{G}$ that dominates $\mathrm{I}$ is denoted by $\gamma_{\mathrm{I}}(\mathrm{G})$, and by $\gamma^{\mathrm{i}}(\mathrm{G})$ we denote the largest $\gamma_{\mathrm{I}}(\mathrm{G})$ over all independent sets $\mathrm{I}$ in G. For an arbitrary graph $\mathrm{G}$, it is known that $\gamma_{\mathrm{F}}(\mathrm{G})$ $\geq \gamma^{\mathrm{i}}(\mathrm{G})$. We call $\gamma^{\mathrm{i}}(\mathrm{G})$ an independence domination number of $\mathrm{G}$.

Proposition 6. $\gamma^{\mathrm{i}}\left(\mathrm{G}^{*}\right)=4$.

Proof. There are forty four independent sets in $\mathrm{G}^{*}$ of different sizes. They can be classified into three categories. Category $\mathrm{A}$ consists of a collection $\mathrm{A}_{1}$ of independent sets in which $u_{1}$ is present; Category $B$ consists of a collection $A_{2}$ of independent sets in which the neighbors of $\mathrm{u}_{1}$ are present and Category $\mathrm{C}$ consists of a collection $\mathrm{A}_{3}$ of independent sets in which neither $\mathrm{u}_{1}$ nor its neighbors are present. We have found that the number of sets of category A is 21; that of category B is 21 ; and that of category $\mathrm{C}$ is 2 . We furnish those sets here for verification along with their dominating sets. Let $\left(\mathrm{A}_{\mathrm{i}}, \mathrm{D}_{\mathrm{i}}\right),\left(\mathrm{B}_{\mathrm{j}}, \mathrm{D}_{\mathrm{j}}{ }^{*}\right)$ and $\left(\mathrm{C}_{\mathrm{k}}, \mathrm{D}_{\mathrm{k}}{ }^{* *}\right)$ denote the respective independent sets along with their dominating sets of the three categories in order. We find that $\left|D_{i}\right|$ or $\left|D_{j}^{*}\right|$ or $\left|D_{k}^{* *}\right|$ is either 3 or 4 .

$\left(\mathrm{A}_{1}, \mathrm{D}_{1}\right)=\left(\left\{\mathrm{u}_{1}, \mathrm{u}_{11}, \mathrm{u}_{12}, \mathrm{u}_{14}, \mathrm{u}_{16}, \mathrm{u}_{18}, \mathrm{u}_{22}\right\},\left\{\mathrm{u}_{2}\right.\right.$, $\left.\left.\mathrm{u}_{15}, \mathrm{u}_{17}\right\}\right)$;

$\left(\mathrm{A}_{2}, \mathrm{D}_{2}\right)=\left(\left\{\mathrm{u}_{1}, \mathrm{u}_{11}, \mathrm{u}_{12}, \mathrm{u}_{14}, \mathrm{u}_{16}, \mathrm{u}_{18}, \mathrm{u}_{23}\right\},\left\{\mathrm{u}_{2}\right.\right.$, $\left.\left.\mathrm{u}_{15}, \mathrm{u}_{17}, \mathrm{u}_{22}\right\}\right)$;

$\left(A_{3}, D_{3}\right)=\left(\left\{u_{1}, u_{11}, u_{12}, u_{14}, u_{16}, u_{19}, u_{22}\right\},\left\{u_{2}\right.\right.$, $\left.\left.\mathrm{u}_{15}, \mathrm{u}_{17}\right\}\right)$;
$\left(\mathrm{A}_{4}, \mathrm{D}_{4}\right)=\left(\left\{\mathrm{u}_{1}, \mathrm{u}_{11}, \mathrm{u}_{12}, \mathrm{u}_{14}, \mathrm{u}_{16}, \mathrm{u}_{19}, \mathrm{u}_{23}\right\},\left\{\mathrm{u}_{2}\right.\right.$, $\left.\left.\mathrm{u}_{15}, \mathrm{u}_{17}, \mathrm{u}_{22}\right\}\right)$;

$\left(\mathrm{A}_{5}, \mathrm{D}_{5}\right)=\left(\left\{\mathrm{u}_{1}, \mathrm{u}_{11}, \mathrm{u}_{12}, \mathrm{u}_{14}, \mathrm{u}_{18}, \mathrm{u}_{20}, \mathrm{u}_{23}\right\},\left\{\mathrm{u}_{2}\right.\right.$, $\left.\left.\mathrm{u}_{13}, \mathrm{u}_{15}, \mathrm{u}_{22}\right\}\right)$;

$\left(A_{6}, D_{6}\right)=\left(\left\{u_{1}, u_{11}, u_{12}, u_{13}, u_{14}, u_{16}, u_{22}\right\},\left\{u_{2}\right.\right.$, $\left.\left.\mathrm{u}_{15}, \mathrm{u}_{17}\right\}\right)$; 
$\left(A_{7}, D_{7}\right)=\left(\left\{u_{1}, u_{11}, u_{12}, u_{13}, u_{14}, u_{16}, u_{23}\right\},\left\{u_{2}\right.\right.$, $\left.\left.\mathrm{u}_{15}, \mathrm{u}_{17}, \mathrm{u}_{22}\right\}\right)$;

$\left(A_{8}, D_{8}\right)=\left(\left\{u_{1}, u_{12}, u_{13}, u_{14}, u_{16}, u_{22}\right\},\left\{u_{2}, u_{15}\right.\right.$, $\left.\left.\mathrm{u}_{17}\right\}\right)$;

$\left(A_{9}, D_{9}\right)=\left(\left\{u_{1}, u_{12}, u_{13}, u_{14}, u_{16}, u_{23}\right\},\left\{u_{2}, u_{15}\right.\right.$, $\left.\left.\mathrm{u}_{17}, \mathrm{u}_{22}\right\}\right)$;

$\left(\mathrm{A}_{10}, \mathrm{D}_{10}\right)=\left(\left\{\mathrm{u}_{1}, \mathrm{u}_{11}, \mathrm{u}_{13}, \mathrm{u}_{14}, \mathrm{u}_{16}, \mathrm{u}_{22}\right\},\left\{\mathrm{u}_{2}, \mathrm{u}_{15}\right.\right.$, $\left.\mathrm{u}_{17}\right\}$ );

$\left(A_{11}, D_{11}\right)=\left(\left\{u_{1}, u_{11}, u_{13}, u_{14}, u_{16}, u_{23}\right\},\left\{u_{2}, u_{15}\right.\right.$, $\left.\left.\mathrm{u}_{17}, \mathrm{u}_{22}\right\}\right)$;

$\left(\mathrm{A}_{12}, \mathrm{D}_{12}\right)=\left(\left\{\mathrm{u}_{1}, \mathrm{u}_{11}, \mathrm{u}_{12}, \mathrm{u}_{14}, \mathrm{u}_{16}, \mathrm{u}_{22}\right\},\left\{\mathrm{u}_{2}, \mathrm{u}_{15}\right.\right.$, $\left.\left.\mathrm{u}_{17}\right\}\right)$

$\left(\mathrm{A}_{13}, \mathrm{D}_{13}\right)=\left(\left\{\mathrm{u}_{1}, \mathrm{u}_{11}, \mathrm{u}_{12}, \mathrm{u}_{14}, \mathrm{u}_{16}, \mathrm{u}_{23}\right\},\left\{\mathrm{u}_{2}, \mathrm{u}_{15}\right.\right.$, $\left.\left.\mathrm{u}_{17}, \mathrm{u}_{22}\right\}\right)$;

$\left(\mathrm{A}_{14}, \mathrm{D}_{14}\right)=\left(\left\{\mathrm{u}_{1}, \mathrm{u}_{11}, \mathrm{u}_{12}, \mathrm{u}_{13}, \mathrm{u}_{16}, \mathrm{u}_{22}\right\},\left\{\mathrm{u}_{2}, \mathrm{u}_{15}\right.\right.$, $\left.\left.\mathrm{u}_{17}\right\}\right)$

$\left(\mathrm{A}_{15}, \mathrm{D}_{15}\right)=\left(\left\{\mathrm{u}_{1}, \mathrm{u}_{11}, \mathrm{u}_{12}, \mathrm{u}_{13}, \mathrm{u}_{16}, \mathrm{u}_{23}\right\},\left\{\mathrm{u}_{2}, \mathrm{u}_{15}\right.\right.$, $\left.\left.\mathrm{u}_{17}, \mathrm{u}_{22}\right\}\right)$;

$\left(\mathrm{A}_{16}, \mathrm{D}_{16}\right)=\left(\left\{\mathrm{u}_{1}, \mathrm{u}_{11}, \mathrm{u}_{12}, \mathrm{u}_{13}, \mathrm{u}_{14}, \mathrm{u}_{22}\right\},\left\{\mathrm{u}_{2}, \mathrm{u}_{15}\right.\right.$, $\left.\left.\mathrm{u}_{23}\right\}\right)$;

$\left(A_{17}, D_{17}\right)=\left(\left\{u_{1}, u_{11}, u_{12}, u_{13}, u_{14}, u_{23}\right\},\left\{u_{2}, u_{15}\right.\right.$, $\left.\mathrm{u}_{22}\right\}$ );

$\left(\mathrm{A}_{18}, \mathrm{D}_{18}\right)=\left(\left\{\mathrm{u}_{1}, \mathrm{u}_{13}, \mathrm{u}_{14}, \mathrm{u}_{16}, \mathrm{u}_{22}\right\},\left\{\mathrm{u}_{2}, \mathrm{u}_{17}\right\}\right) ;$

$\left(A_{19}, D_{19}\right)=\left(\left\{u_{1}, u_{13}, u_{14}, u_{16}, u_{23}\right\},\left\{u_{2}, u_{17}\right.\right.$, $\left.\left.\mathrm{u}_{22}\right\}\right)$;

$\left(\mathrm{A}_{20}, \mathrm{D}_{20}\right)=\left(\left\{\mathrm{u}_{1}, \mathrm{u}_{11}, \mathrm{u}_{12}, \mathrm{u}_{14}, \mathrm{u}_{16}, \mathrm{u}_{18}, \mathrm{u}_{19}, \mathrm{u}_{22}\right\}\right.$, $\left.\left\{\mathrm{u}_{2}, \mathrm{u}_{13}, \mathrm{u}_{15}, \mathrm{u}_{17}\right\}\right)$;

$\left(\mathrm{A}_{21}, \mathrm{D}_{21}\right)=\left(\left\{\mathrm{u}_{1}, \mathrm{u}_{11}, \mathrm{u}_{12}, \mathrm{u}_{14}, \mathrm{u}_{16}, \mathrm{u}_{18}, \mathrm{u}_{19}, \mathrm{u}_{23}\right\}\right.$, $\left.\left\{\mathrm{u}_{2}, \mathrm{u}_{15}, \mathrm{u}_{17}, \mathrm{u}_{22}\right\}\right)$;

$\left(\mathrm{B}_{1}, \mathrm{D}_{1}{ }^{*}\right)=\left(\left\{\mathrm{u}_{2}, \mathrm{u}_{3}, \mathrm{u}_{4}, \mathrm{u}_{5}, \mathrm{u}_{6}, \mathrm{u}_{7}, \mathrm{u}_{10}, \mathrm{u}_{15}, \mathrm{u}_{19}\right.\right.$, $\left.\left.\mathrm{u}_{22}\right\},\left\{\mathrm{u}_{1}, \mathrm{u}_{11}, \mathrm{u}_{17}\right\}\right)$;

$\left(B_{2}, D_{2}{ }^{*}\right)=\left(\left\{u_{2}, u_{3}, u_{4}, u_{5}, u_{6}, u_{7}, u_{10}, u_{15}, u_{19}\right.\right.$, $\left.\left.\mathrm{u}_{23}\right\},\left\{\mathrm{u}_{1}, \mathrm{u}_{11}, \mathrm{u}_{17}, \mathrm{u}_{22}\right\}\right)$;

$\left(\mathrm{B}_{3}, \mathrm{D}_{3}{ }^{*}\right)=\left(\left\{\mathrm{u}_{2}, \mathrm{u}_{3}, \mathrm{u}_{4}, \mathrm{u}_{5}, \mathrm{u}_{6}, \mathrm{u}_{7}, \mathrm{u}_{15}, \mathrm{u}_{19}, \mathrm{u}_{22}\right\}\right.$, $\left.\left\{\mathrm{u}_{1}, \mathrm{u}_{11}, \mathrm{u}_{17}\right\}\right)$;

$\left(\mathrm{B}_{4}, \mathrm{D}_{4}{ }^{*}\right)=\left(\left\{\mathrm{u}_{2}, \mathrm{u}_{3}, \mathrm{u}_{4}, \mathrm{u}_{5}, \mathrm{u}_{6}, \mathrm{u}_{7}, \mathrm{u}_{15}, \mathrm{u}_{19}, \mathrm{u}_{23}\right\}\right.$, $\left.\left\{\mathrm{u}_{1}, \mathrm{u}_{11}, \mathrm{u}_{17}, \mathrm{u}_{22}\right\}\right)$;

$\left(\mathrm{B}_{5}, \mathrm{D}_{5}{ }^{*}\right)=\left(\left\{\mathrm{u}_{3}, \mathrm{u}_{4}, \mathrm{u}_{5}, \mathrm{u}_{6}, \mathrm{u}_{7}, \mathrm{u}_{10}, \mathrm{u}_{15}, \mathrm{u}_{19}, \mathrm{u}_{22}\right\}\right.$, $\left.\left\{\mathrm{u}_{1}, \mathrm{u}_{11}, \mathrm{u}_{17}\right\}\right)$;
$\left(\mathrm{B}_{6}, \mathrm{D}_{6}{ }^{*}\right)=\left(\left\{\mathrm{u}_{3}, \mathrm{u}_{4}, \mathrm{u}_{5}, \mathrm{u}_{6}, \mathrm{u}_{7}, \mathrm{u}_{10}, \mathrm{u}_{15}, \mathrm{u}_{19}, \mathrm{u}_{23}\right\}\right.$, $\left.\left\{\mathrm{u}_{1}, \mathrm{u}_{11}, \mathrm{u}_{17}, \mathrm{u}_{22}\right\}\right)$;

$\left(\mathrm{B}_{7}, \mathrm{D}_{7}{ }^{*}\right)=\left(\left\{\mathrm{u}_{2}, \mathrm{u}_{4}, \mathrm{u}_{5}, \mathrm{u}_{6}, \mathrm{u}_{7}, \mathrm{u}_{10}, \mathrm{u}_{15}, \mathrm{u}_{19}, \mathrm{u}_{22}\right\}\right.$, $\left.\left\{\mathrm{u}_{1}, \mathrm{u}_{11}, \mathrm{u}_{17}\right\}\right)$;

$\left(\mathrm{B}_{8}, \mathrm{D}_{8}{ }^{*}\right)=\left(\left\{\mathrm{u}_{2}, \mathrm{u}_{4}, \mathrm{u}_{5}, \mathrm{u}_{6}, \mathrm{u}_{7}, \mathrm{u}_{10}, \mathrm{u}_{15}, \mathrm{u}_{19}, \mathrm{u}_{23}\right\}\right.$, $\left.\left\{\mathrm{u}_{1}, \mathrm{u}_{11}, \mathrm{u}_{17}, \mathrm{u}_{22}\right\}\right)$;

$\left(\mathrm{B}_{9}, \mathrm{D}_{9}{ }^{*}\right)=\left(\left\{\mathrm{u}_{2}, \mathrm{u}_{3}, \mathrm{u}_{5}, \mathrm{u}_{6}, \mathrm{u}_{7}, \mathrm{u}_{10}, \mathrm{u}_{15}, \mathrm{u}_{19}, \mathrm{u}_{22}\right\}\right.$, $\left.\left\{\mathrm{u}_{1}, \mathrm{u}_{11}, \mathrm{u}_{17}\right\}\right)$;

$\left(\mathrm{B}_{10}, \mathrm{D}_{10}{ }^{*}\right)=\left(\left\{\mathrm{u}_{2}, \mathrm{u}_{3}, \mathrm{u}_{5}, \mathrm{u}_{6}, \mathrm{u}_{7}, \mathrm{u}_{10}, \mathrm{u}_{15}, \mathrm{u}_{19}, \mathrm{u}_{23}\right\}\right.$, $\left.\left\{\mathrm{u}_{1}, \mathrm{u}_{11}, \mathrm{u}_{17}, \mathrm{u}_{22}\right\}\right)$;

$\left(\mathrm{B}_{11}, \mathrm{D}_{11}{ }^{*}\right)=\left(\left\{\mathrm{u}_{2}, \mathrm{u}_{3}, \mathrm{u}_{4}, \mathrm{u}_{6}, \mathrm{u}_{7}, \mathrm{u}_{10}, \mathrm{u}_{15}, \mathrm{u}_{19}, \mathrm{u}_{22}\right\}\right.$, $\left.\left\{\mathrm{u}_{1}, \mathrm{u}_{11}, \mathrm{u}_{17}\right\}\right)$;

$\left(\mathrm{B}_{12}, \mathrm{D}_{12}{ }^{*}\right)=\left(\left\{\mathrm{u}_{2}, \mathrm{u}_{3}, \mathrm{u}_{4}, \mathrm{u}_{6}, \mathrm{u}_{7}, \mathrm{u}_{10}, \mathrm{u}_{15}, \mathrm{u}_{19}, \mathrm{u}_{23}\right\}\right.$, $\left.\left\{\mathrm{u}_{1}, \mathrm{u}_{11}, \mathrm{u}_{17}, \mathrm{u}_{22}\right\}\right)$;

$\left(\mathrm{B}_{13}, \mathrm{D}_{13}{ }^{*}\right)=\left(\left\{\mathrm{u}_{2}, \mathrm{u}_{3}, \mathrm{u}_{4}, \mathrm{u}_{5}, \mathrm{u}_{6}, \mathrm{u}_{10}, \mathrm{u}_{15}, \mathrm{u}_{23}\right\}\right.$, $\left.\left\{\mathrm{u}_{1}, \mathrm{u}_{11}, \mathrm{u}_{22}\right\}\right)$;

$\left(\mathrm{B}_{14}, \mathrm{D}_{14}{ }^{*}\right)=\left(\left\{\mathrm{u}_{2}, \mathrm{u}_{3}, \mathrm{u}_{4}, \mathrm{u}_{5}, \mathrm{u}_{7}, \mathrm{u}_{10}, \mathrm{u}_{15}, \mathrm{u}_{19}, \mathrm{u}_{22}\right\}\right.$, $\left.\left\{\mathrm{u}_{1}, \mathrm{u}_{11}, \mathrm{u}_{17}\right\}\right)$;

$\left(\mathrm{B}_{15}, \mathrm{D}_{15}{ }^{*}\right)=\left(\left\{\mathrm{u}_{2}, \mathrm{u}_{3}, \mathrm{u}_{4}, \mathrm{u}_{5}, \mathrm{u}_{7}, \mathrm{u}_{10}, \mathrm{u}_{15}, \mathrm{u}_{19}, \mathrm{u}_{23}\right\}\right.$, $\left.\left\{\mathrm{u}_{1}, \mathrm{u}_{11}, \mathrm{u}_{17}, \mathrm{u}_{22}\right\}\right)$;

$\left(\mathrm{B}_{16}, \mathrm{D}_{16}{ }^{*}\right)=\left(\left\{\mathrm{u}_{2}, \mathrm{u}_{3}, \mathrm{u}_{4}, \mathrm{u}_{5}, \mathrm{u}_{6}, \mathrm{u}_{10}, \mathrm{u}_{15}, \mathrm{u}_{19}, \mathrm{u}_{22}\right\}\right.$, $\left.\left\{\mathrm{u}_{1}, \mathrm{u}_{11}, \mathrm{u}_{17}\right\}\right)$;

$\left(\mathrm{B}_{17}, \mathrm{D}_{17}{ }^{*}\right)=\left(\left\{\mathrm{u}_{2}, \mathrm{u}_{3}, \mathrm{u}_{4}, \mathrm{u}_{5}, \mathrm{u}_{6}, \mathrm{u}_{10}, \mathrm{u}_{15}, \mathrm{u}_{19}, \mathrm{u}_{23}\right\}\right.$, $\left.\left\{\mathrm{u}_{1}, \mathrm{u}_{11}, \mathrm{u}_{17}, \mathrm{u}_{22}\right\}\right)$;

$\left(\mathrm{B}_{18}, \mathrm{D}_{18}{ }^{*}\right)=\left(\left\{\mathrm{u}_{3}, \mathrm{u}_{4}, \mathrm{u}_{5}, \mathrm{u}_{6}, \mathrm{u}_{10}, \mathrm{u}_{15}, \mathrm{u}_{19}, \mathrm{u}_{22}\right\}\right.$, $\left.\left\{\mathrm{u}_{1}, \mathrm{u}_{11}, \mathrm{u}_{17}\right\}\right)$;

$\left(\mathrm{B}_{19}, \mathrm{D}_{19}{ }^{*}\right)=\left(\left\{\mathrm{u}_{3}, \mathrm{u}_{4}, \mathrm{u}_{5}, \mathrm{u}_{6}, \mathrm{u}_{10}, \mathrm{u}_{15}, \mathrm{u}_{19}, \mathrm{u}_{23}\right\}\right.$, $\left.\left\{\mathrm{u}_{1}, \mathrm{u}_{11}, \mathrm{u}_{17}, \mathrm{u}_{22}\right\}\right)$;

$\left(\mathrm{B}_{20}, \mathrm{D}_{20}{ }^{*}\right)=\left(\left\{\mathrm{u}_{2}, \mathrm{u}_{3}, \mathrm{u}_{4}, \mathrm{u}_{5}, \mathrm{u}_{15}, \mathrm{u}_{20}, \mathrm{u}_{22}\right\}, \quad\left\{\mathrm{u}_{1}\right.\right.$, $\left.\left.\mathrm{u}_{11}, \mathrm{u}_{13}, \mathrm{u}_{17}\right\}\right)$;

$\left(\mathrm{B}_{21}, \mathrm{D}_{21}{ }^{*}\right)=\left(\left\{\mathrm{u}_{2}, \mathrm{u}_{3}, \mathrm{u}_{4}, \mathrm{u}_{5}, \mathrm{u}_{15}, \mathrm{u}_{20}, \mathrm{u}_{23}\right\},\left\{\mathrm{u}_{1}\right.\right.$, $\left.\left.\mathrm{u}_{11}, \mathrm{u}_{19}, \mathrm{u}_{22}\right\}\right)$;

$\left(\mathrm{C}_{1}, \mathrm{D}_{1}{ }^{* * *}\right)=\left(\left\{\mathrm{u}_{11}, \mathrm{u}_{12}, \mathrm{u}_{13}, \mathrm{u}_{14}, \mathrm{u}_{16}, \mathrm{u}_{22}\right\},\left\{\mathrm{u}_{2}, \mathrm{u}_{15}\right.\right.$, $\left.\mathrm{u}_{17}\right\}$ );

$\left(\mathrm{C}_{2}, \mathrm{D}_{2}^{* *}\right)=\left(\left\{\mathrm{u}_{11}, \mathrm{u}_{12}, \mathrm{u}_{13}, \mathrm{u}_{14}, \mathrm{u}_{16}, \mathrm{u}_{23}\right\},\left\{\mathrm{u}_{2}, \mathrm{u}_{15}\right.\right.$, $\left.\left.\mathrm{u}_{17}, \mathrm{u}_{22}\right\}\right)$. 
Hence by the definition of the independence domination number, we conclude that $\gamma^{\mathrm{i}}\left(\mathrm{G}^{*}\right)=4$.

\section{Scope Of Practical Applicability Of The Results}

The OSN(On-line social networks) of type Facebook have progressed as a hot topic within the network science community. Various research points that OSNs agrees with many properties in common with several other complex networks like: distributions obeying power-law degree [13,14], high local clustering [15], constant or varying diameter with network size $[15,16]$, localized information flow bottlenecks $[17,18]$ etc., A number of models were designed to simulate them[19, 20], and a typical model that absorbs asymptotically all these properties is the GEO$\mathrm{P}$ (geometric protean model) [21]. A unique feature of GEO-P over other models $[22,23]$ is that exhibits the underlying feature of a metric space. This metric space yields a Blau space construction in the social sciences called [24]. The agents in Blau space, of a social network correspond to points in a metric space, and the relative position of these nodes supports the homophily principle of [25]. Domination and dominating sets assumes a significant role with lot of application to problems in realworld networks. Dominating sets occurs in network controllability [26], as a measure of centrality in efficient data routing [27], and to detect biologically pertinent proteins in protein-protein interaction networks [28].

\section{Conclusion And Further Research Challenges}

In this paper we have studied several variations in the concept of domination with respect to vertices of a graph. Similar formulations can be probed with reference to edges and that will open up a plethora of opportunities. For instance consider the bondage domination number $\gamma_{b}$ of a graph $G$, by which we mean the minimum cardinality of an edge subset $E_{1}$ of $E(G)$ to be removed from $E(G)$ so that $\gamma_{b}\left(G-E_{1}\right)$ $>\gamma(\mathrm{G})$ or the strong bondage domination number $\gamma_{\mathrm{sb}}$, by which we mean the minimum cardinality of an edge subset $E_{1}$ of $E(G)$ such that $\gamma_{s}\left(G-E_{1}\right)>\gamma_{s}(G)$. Interestingly for the RNPCG discussed in the above we have $\gamma_{\mathrm{b}}\left(\mathrm{G}^{*}\right)=\gamma_{\mathrm{sb}}\left(\mathrm{G}^{*}\right)=1$. Several other interesting properties around these parameters are observed and we will revert back to it elsewhere. Moreover the effect of the domination variations considered here with reference to the concept of a) vertex or edge criticality or b) Nordhaus-Gaddum type inequalities and the associated extremal graph characterization, are being considered by us and soon we hope to announce new results as a sequel to this paper. In social networks, One can consider the assumption that dominating sets with minimum order contain agents that strongly influence the rest of the members in the network. The deemed elites are those who influences stealthily on the ambitious network, are considered in the sociology literature [6]. In order to detect elites is through their high degree and through k-cores [6]. Another way is to find for them inside a minimum order dominating set. If dominating sets with minimum order possess much smaller order than the size of the network then that brings down the cost of computation of identifying the elites. It is in Network theory we notice that popularity is a side effect of being connected. The Erdos number computation is necessary as they provide a meta hub to focus oneself conceptually. One can also refer [30-32] for more on Erdos numbers. In future we wish to widen our analysis of various domination numbers considered here to other data sets belonging to other social and biological networks. 


\section{ACKNOWLEDGEMENT}

Dr V. Yegnanarayanan thanks Department of Science \& Technology (DST), Government of India for financial support via sanction order No. : SR/FST/MSI$107 / 2015$.

\section{REFERENCES}

1. Bollobas.B. Graph Theory. An Introductory Course. Springer.1979.|

2. Bondy J.A, Murty U.S.R. Graph theory with applications. Macmillan 1976.

3. Harary, F. Graph Theory. Addison-Wesley. Massachusetts 1969.|

4. Wilson.J, Watkins John J.J. Graphs: An Introductory Approach. Wiley \& Sons. 1990.

5. Haynes, T.W, Hedetniemi, S.T. and Slater, P.J. Fundamentals of domination in graphs. Marcel, Dekkar. Inc-New York .1998.

6. Joanna Cyman. The Outer-Connected domination number of a graph. Autralasian Journal of Combinatorics. 2007; 38: 35-46.

7. Karami H, Khoeilar R, Sheikholeslami SM. Doubly Connected Domination Subdivision Numbers of Graphs. MATEMA. 2012; 64(3): 232-239.

8. http://pajek.imfm.si/doku.php?id=download

9. Yegnanarayanan V, Umamaheswari GK. On Rolf Nevanlinna Prize Winners Collaboration Graph. JCMCC. 2011; 79: 43-58.

10. Yegnanarayanan V, Umamaheswari GK. On Rolf Nevanlinna Prize Winners Collaboration Graph-II. International Journal of Scientific and Research Publications. 2012; 2(4): 354-367.

11. Yegnanarayanan V, Umamaheswari GK. On Rolf Nevanlinna Prize Winners Collaboration Graph-III. Journal of Mathematical and Computational Sciences. 2013; 3(2): 419-455.

12. Yegnanarayanan V, Logeshwary B. On Graph Domination Numbers. International Journal of Pure and Applied Mathematics. 2015; Vol 105; No.4; 751-761.

13. Barab’asi, A.L. Albert R. Emergence of scaling in random networks. Science. 1999.286: $509-512$.

14. Faloutsos M Faloutsos P, Faloutsos C. On power-law relationships of the internet topology. SIGCOMM. Comput Commun Rev. 1999, 29 251-262.

15. Watts D.J, Strogatz S.H. Collective dynamics of "small-world" networks. Nature. 393.1998, $440-442$.

16. Leskovec J, Kleinberg J, Faloutsos C. Graph evolution: Densification and shrinking diameters. ACM Trans. Knowl Discov Data. 1. 2007 1-41.

17. Estrada E. Spectral scaling and good expansion properties in complex networks. Europhysics Letters . 2006, 73, 649.

18. Leskovec J, Lang K.J, Dasgupta A, Mahoney M.W. Community structure in large networks: Natural cluster sizes and the absence of large well-defined clusters.Internet Mathematics. $2009,6,29-123$.

19. Kim M, Leskovec J. Multiplicative attribute graph model of real-world networks. Internet Mathematics. 2012, 8, 113-160.

20. Kolda T.G, Pinar A, Plantenga A, Seshadhri C. A scalable generative graph model with community structure. SIAM J. SCI. COMPUT. 2014, Vol. 36, No. 5, pp. C424-C452.

21. Bonato A, Janssen J , Pra lat J, P. Geometric protean graphs. Internet Mathematics. 2012, 8, $2-28$.

22. Kumar R, Raghavan P, Rajagopalan S, Sivakumar S, Tomkins A. Stochastic models for the web graph. In: Proceedings of the 41st Annual Symposium on Foundations of Computer Science. 2000.

23. Leskovec J, Chakrabarti D, Kleinberg J, Faloutsos C, Ghahramani Z. Kronecker graphs: An approach to modeling networks. Journal of Machine Learning Research. 2010, 11, 985-1042.

24. McPherson J.M, Ranger-Moore J.R. Evolution on a dancing landscape: Organizations and networks in dynamic blau space. Social Forces. 1991, 70, 19-42.

25. McPherson M, Smith-Lovin J.M. Birds of a feather: Homophily in social networks. Annual Review of Sociology. 2001, 27, 415-444.

26. Cowan N.J, Chastain E.J, Vilhena D.A, Freudenberg J.S, Bergstrom C.T. Nodal dynamics, not degree distributions, determine the structural controllability of complex networks. PLOS ONE. 2012, 7, e38398. 
Computation of various domination numbers

27. Stojmenovic I, Seddigh M, Zunic J. Dominating sets and neighbor elimination-based broadcasting algorithms in wireless networks. IEEE Transactions on Parallel and Distributed Systems. 2002, 13, 14-25.

28. Milenkovi'c T, Memi"sevi'c T, Bonato A, Pr"zulj N. Dominating biological networks. PLOS ONE. 2013, 6, No.8, e23016.

29. Corominas-Murtra B, Fuchs B, Thurner S. Detection of the elite structure in a virtual multiplex social system by means of a generalized k-core. PLOS ONE. 2014, 1-14. DOI:10.1371/journal.pone.0112606 December 26, 2014, 1-19.

30. Goffman, Casper. And what is your Erdos number?. American Mathematical Monthly. 1969, 76, No. 7, 791.

31. Grossman J. The Erdos number project, 2015. http://wwwp.oakland.edu/enp/erdpaths/

32. Kashyap Dixit, Kameshwaran S, Sandeep Mehta, Vinayaka Pandit, Viswanadham N. Towards Simultaneously Exploiting structure and outcomes in interaction networks for node rankings. IBM Research Report. Feb 2009, R109002. 